\title{
The role of islet lipid composition remodeling in regulation of beta- cell death via ADP-ribosyl-acceptor glycohydrolase ARH3 signaling in insulitis
}

Ernesto S. Nakayasu'1,12,13, Cailin Deiter ${ }^{2}$, Jennifer E. Kyle ${ }^{1}$, Michelle A. Guney², Dylan Sarbaugh$^{2}$, Ruichuan Yin ${ }^{3}$, Yi Cui ${ }^{4,5}$, Carrie D. Nicora ${ }^{1}$, Farooq Syed ${ }^{6}$, Jonas JuanMateu $^{7,8}$, Raghavendra G. Mirmira9 ${ }^{9}$, Carmella Evans-Molina ${ }^{6}$, Decio L. Eizirik ${ }^{7,10}$, BobbieJo M. Webb-Robertson ${ }^{1,11}$, Kristin Burnum-Johnson ${ }^{4}$, Galya Orr ${ }^{4}$, Julia Laskin ${ }^{3}$, Thomas O. Metz ${ }^{1}$, Lori Sussel², Charles Ansong ${ }^{1,12}$

${ }^{1}$ Biological Sciences Division, Pacific Northwest National Laboratory, Richland, WA, USA ${ }^{2}$ Barbara Davis Center for Diabetes, University of Colorado Anschutz Medical Center, Aurora, CO, USA

${ }^{3}$ Department of Chemistry, Purdue University, West Lafayette, IN, USA

${ }^{4}$ Environmental and Molecular Sciences Laboratory, Pacific Northwest National Laboratory, Richland, WA, USA

${ }^{5}$ Media Lab, Massachusetts Institute of Technology, Cambridge, MA, USA

${ }^{6}$ Center for Diabetes and Metabolic Diseases and the Herman B Wells Center for Pediatric Research, Indiana University School of Medicine, Indianapolis, IN, USA

${ }^{7}$ ULB Center for Diabetes Research, Université Libre de Bruxelles (ULB), Brussels, Belgium

${ }^{8}$ Centre for Genomic Regulation (CRG), The Barcelona Institute of Science and Technology, Barcelona, Spain

${ }^{9}$ Kovler Diabetes Center and Department of Medicine, The University of Chicago, Chicago, IL, USA

${ }^{10}$ Indiana Biosciences Research Institute Diabetes Center, Indianapolis, IN, USA

${ }^{11}$ Department of Biostatistics and Informatics, University of Colorado Anschutz Medical Center, Aurora, CO, USA

${ }^{12}$ Senior Author

${ }^{13}$ Lead Contact

Correspondence: ernesto.nakayaus@pnnl.gov (E.S.N.) and charles.ansong@pnnl.gov (C.A) 


\section{Summary}

Lipids have been implicated as mediators of insulitis and $\beta$-cell death in type 1 diabetes development, but the mechanisms underlying this association are poorly understood. Here, we investigated the changes in islet/ $\beta$-cell lipid composition using three models of insulitis: human islets and EndoC- $\beta \mathrm{H} 1 \beta$-cells treated with the cytokines IL-1 $\beta$ and IFN- $\gamma$, and islets from non-obese diabetic mice. Across all three models, lipidomic analyses showed a consistent change in abundance of the lysophosphatidylcholine, phosphatidylcholine and triacylglycerol species. We also showed that lysophosphatidylcholine and its biosynthetic enzyme PLA2G6 are enriched in murine islets. We determined that the ADP-ribosyl-acceptor glycohydrolase ARH3 is regulated by cytokines downstream of PLA2G6, which in turn regulates proteins involved in apoptosis, lipid metabolism, antigen processing and presentation and chemokines. ARH3 reduced cytokine-induced apoptosis, which may represent a negative feedback mechanism. Overall, these data show the importance of lipid metabolism in regulating $\beta$ cell death in type 1 diabetes.

Keywords: Type 1 diabetes, insulitis, lipidomics, phospholipase, poly(ADP)ribosylation, $\beta$-cell death

\section{Highlights:}

- Lipidomics of 3 insulitis models revealed commonly regulated lipid classes.

- Identification of 35 proteins regulated by cytokines via PLA2G6 signaling.

- ARH3 reduces cytokine-induced apoptosis via PLA2G6 regulation.

- $\mathrm{ARH} 3$ regulates the levels of proteins related to insulitis and type 1 diabetes. 


\section{INTRODUCTION}

Type 1 diabetes (T1D) affects over 1.25 million people in the U.S. and is characterized by the autoimmune destruction of the insulin-producing $\beta$ cells of the pancreas (DiMeglio et al., 2018). This results in the disruption of blood glucose regulation, the development of microvascular and macrovascular complications, and ultimately reduces life expectancy of individuals with T1D by approximately 12 years (Huo et al., 2016). Currently, the treatment of T1D relies on exogenous insulin administration and there is no cure or permanent remission from the disease. Therefore, there is an urgent need to better understand the mechanisms that contribute to $\beta$-cell loss in order to inform the development of novel treatment therapies.

Lipids play major roles in all tissues of the body, being the major structural component of membranes, energy storage molecules and cell-signaling mediators. T1D is associated with changes in serum lipid profiles after disease onset, including increases in blood triacylglycerol and cholesterol levels, which are often associated with poor glycemic control (Verges, 2009). However, limited information is available regarding the roles of lipids in contributing to disease pathogenesis. For instance, the Oresic group found that circulating lipids function as biomarkers for autoimmunity and T1D progression (Lamichhane et al., 2018; Oresic et al., 2013). In terms of cell signaling, lipids have been shown to be important mediators of the islet inflammatory process (insulitis) (Bone et al., 2015; Dobrian et al., 2019; Syed et al., 2019). During insulitis, pro-inflammatory cytokines activate phospholipases, such as inducible phospholipase A2 (PLA2), leading to the cleavage of phosphatidylcholine (PC) into lysophosphatidylcholine (LPC) (Barbour et al., 2015; Bone et al., 2015; Lei et al., 2014). This process also leads to the release of fatty 
acids, such as arachidonic acid, which can be converted into prostaglandins, leukotrienes and thromboxanes that activate pro-apoptotic signaling and contribute to $\beta$-cell death (Chambers et al., 2007; Ma et al., 1996).

Currently, the role of the islet lipidome during the progression of T1D is poorly understood. Mass spectrometry analysis of islets has identified LPC and ceramides as important molecules in $\beta$-cell death (Lei et al., 2014). However, the lipidomics coverage in that study was limited and recent advances in technology can provide a more comprehensive coverage of the islet lipidome. Here, we used 3 models of insulitis and type 1 diabetes progression to study the changes in islet/ $\beta$ cell lipid composition during this process. Unbiased lipidomics analyses were performed in 1) human islets and 2) a human $\beta$-cell line exposed to the proinflammatory cytokines IL-1 $\beta$ and IFN- $\gamma$, that induce a molecular signature similar to the one observed in $\beta$ cells from patients affected by type 1 diabetes (Eizirik et al., 2020), and 3) in islets from non-obese diabetic (NOD) mice. The analysis showed a consistent regulation of LPC, PC with long unsaturated fatty acid chains and triacylglycerol species across the different models. To further investigate LPC regulation, we performed mass spectrometry imaging analysis and microscopy of its biosynthetic enzyme PLA2G6 in mouse islets. The results showed that both LPC and PLA2G6 are enriched in islets. We also investigated the signaling mediated by PLA2G6 in mouse Min6 $\beta$ cells using RNAi followed by proteomics analysis. This analysis determined that the ADP-ribosyl-acceptor glycohydrolase ARH3 is regulated by cytokines and, based on RNAi experiments targeting $\mathrm{ARH}$, we observed that this protein provides a complex negative feedback mechanism that reduces cytokine-induced apoptosis. 


\section{MATERIAL AND METHODS}

\section{Mice}

Female 6-week-old non-obese diabetic NOD/ShiLtJ (\#001976) and non-obese diabetesresistant NOR/LtJ (\#002050) mice were purchased from Jackson Labs. Husbandry of mice and experimental procedures were performed according an approved IACUC protocol at the University of Colorado (\#00045). Mice were housed for $<1$ week prior to islet isolation. Approximately $320-520$ islets $(n=3)$ were isolated using Histopaque centrifugation gradient and further handpicking of islets as described previously (Beilke et al., 2005).

\section{Human pancreatic islet and EndoC- $\beta \mathrm{H} 1$ cells}

The lipidomics data of the human islets $(n=10)$ (Supplementary Table 1) and EndoC-

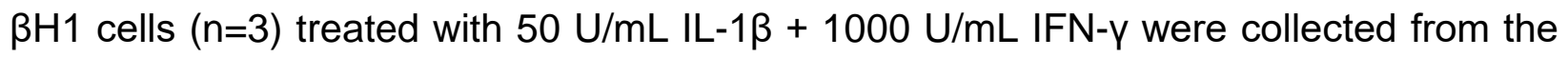
same samples of proteomic analyses carried out by us in (Nakayasu et al., 2020a) and (Ramos-Rodriguez et al., 2019), respectively. Culture maintenance, treatment and harvesting information are described in detail elsewhere (Nakayasu et al., 2020a; RamosRodriguez et al., 2019).

\section{MIN6 $\beta$ cell line culture and treatment}

MIN6 cells were cultured in DMEM containing 10\% FBS and 1\% penicillin-streptomycin and maintained at $37^{\circ} \mathrm{C}$ in $5 \% \mathrm{CO}_{2}$ atmosphere. For knockdown experiments, cells were transfected using Lipofectamine RNAiMAX (Invitrogen) with SMARTpool ONTARGETplus non-targeting scramble siRNA (control) or siRNA targeting either PLA2g6 or ARH3 (Dharmacon). In order to achieve robust knockdown of ARH3, cells were transfected a second time with scramble or ARH3 siRNA $24 \mathrm{~h}$ after the first transfection. 
In experiments utilizing cytokines, cells were treated for $24 \mathrm{~h}$ with $100 \mathrm{ng} / \mathrm{mL}$ IFN-y, 10 $\mathrm{ng} / \mathrm{mL}$ TNF- $\alpha$, and $5 \mathrm{ng} / \mathrm{mL} \mathrm{IL}-1 \beta$.

\section{Lipidomic analysis}

Samples were subjected to metabolite, protein and lipid extraction (MPLEx) (Nakayasu et al., 2016) with all the procedure done on ice or $4^{\circ} \mathrm{C}$ to reduce sample degradation. Cells and islets were suspended in water and extracted with 5 volumes of cold $\left(-20^{\circ} \mathrm{C}\right)$ chloroform/methanol solution $(2 / 1, v / v)$ by incubating $5 \mathrm{~min}$ on ice and vigorously vortexing. Samples were centrifuged for $10 \mathrm{~min}$ at $16,000 \mathrm{xg}$ at $4^{\circ} \mathrm{C}$ to separate different liquid phases. Solvent layers containing metabolites and lipids were collected into glass autosampler vials and dried in a vacuum centrifuge. Protein pellets were washed by adding $1 \mathrm{~mL}$ of cold $\left(-20^{\circ} \mathrm{C}\right)$ methanol and centrifuging $10 \mathrm{~min}$ at $16,000 \mathrm{xg}$ at $4^{\circ} \mathrm{C}$. The supernatant was discarded, and pellets were dried in a vacuum centrifuge before digesting with trypsin.

Extracted lipids were resuspended in methanol and loaded on a reverse phase column connected to a NanoAcquity UPLC system (Waters) and interfaced with a Velos Orbitrap mass spectrometer (Thermo Fisher) (Dautel et al., 2017) (see Supplementary

Table 2 for parameters). Lipid species were identified using LIQUID (Dautel et al., 2017) and manually validated based on the retention time, precursor isotopic profile, diagnostic fragments from head groups and fatty acyl chains. Isomers were named in alphabetical order based on their elution times. The features of the identified lipid species were extracted and aligned using targeted peak detection in MZmine (Pluskal et al., 2010). Peak intensity tolerance was set at $20 \%$ with a noise level of $5 e 3$, while the mass and retention time tolerances were $0.008 \mathrm{~m} / \mathrm{z}$ and $0.3 \mathrm{~min}$, respectively. Chromatograms were 
built with a time span of $0.1 \mathrm{~min}$, minimum height of $5 \mathrm{e} 3$ and mass tolerance of $0.008 \mathrm{~m} / \mathrm{z}$. Peaks were then aligned with joint aligner with mass tolerance of $0.01 \mathrm{~m} / \mathrm{z}$, retention time tolerance of $0.2 \mathrm{~min}$, and weights of both retention time and $\mathrm{m} / \mathrm{z}$ of 1 . Missing values were filled with gap filling based on the same retention time and mass tolerance of $0.008 \mathrm{~m} / \mathrm{z}$. The lipidomics data were $\log 2$ transformed and subjected to quality control analysis to identify any sample issues via Principal Component Analysis (PCA), robust to missing data for proteomics (3), as well as a robust PCA approach based on the distributional properties of the measured biomolecules for each sample (4). No sample-level issues were detected and subsequently the lipidomics data were evaluated for total abundance bias and, with none found, were global median centered (5). Given the experimental design, statistics were then performed via a standard paired t-test followed by a multiple test Bonferroni correction (6).

\section{Proteomic analysis}

Proteins were dissolved in $50 \mathrm{mM} \mathrm{NH}_{4} \mathrm{HCO}_{3}$ containing $8 \mathrm{M}$ urea and $10 \mathrm{mM}$ dithiothreitol. After incubating for $1 \mathrm{~h}$ at $37^{\circ} \mathrm{C}$ with shaking at $800 \mathrm{rpm}, 400 \mathrm{mM}$ iodoacetamide was added to a final concentration of $40 \mathrm{mM}$, and the mixture incubated for another hour in the dark at room temperature. The reaction mixture was 8-folds diluted with $50 \mathrm{mM}$ $\mathrm{NH}_{4} \mathrm{HCO}_{3}$, and $1 \mathrm{M} \mathrm{CaCl}_{2}$ was added to a final concentration of $1 \mathrm{mM}$. Proteins were digested for $3 \mathrm{~h}$ at $37^{\circ} \mathrm{C}$ using trypsin at 1:50 enzyme:protein ratio. Digested peptides were desalted by solid-phase extraction using C18 cartridges (Discovery, 50 mg, Sulpelco) and dried in a vacuum centrifuge.

Peptides were analyzed on a Waters NanoAquity UPLC system coupled with a QExactive mass spectrometer (see Supplementary Table 2 for parameters). Data were 
processed with MaxQuant software (v.1.5.5.1 and v1.6.14.0) (Cox and Mann, 2008) by matching against the mouse reference proteome database from Uniprot Knowledge Base (downloaded on August 14, 2018 and on August 31, 2020). Searching parameters included protein $\mathrm{N}$-terminal acetylation and oxidation of methionine as variable modifications, and carbamidomethylation of cysteine residues as fixed modification. Mass shift tolerance was used as the default setting of the software. Only fully tryptic digested peptides were considered, allowing up to two missed cleaved sites per peptide. Quantification of proteins was done using the intensity-based absolute quantification (iBAQ) method (Schwanhausser et al., 2011). Data was log2 transformed, and normalized by linear regression and central tendency using InfernoRDN (former Dante) (Polpitiya et al., 2008). Statistically significant proteins were determined by ANOVA or by t-test.

\section{Bioinformatics analysis}

The significantly different lipids and proteins were submitted to ontology/functionenrichment analysis using Lipid MiniOn (Clair et al., 2019) and DAVID (Huang da et al., 2009) tools, respectively. For the Lipid MiniOn analysis, the full list of identified lipids was set as the background and the significantly different species as the query. Ontologies were considered enriched with a $p \leq 0.05$ using the Fisher's exact test. For the DAVID analysis, the differentially abundant proteins were set as the query and the entire genome was set as the background. Only enriched pathways ( $\leq \leq 0.05)$ of the KEGG database were used and they were grouped based on shared proteins using Enrichment Map (Merico et al., 2010).

\section{Tissue processing and immunohistochemistry}


Pancreata were dissected, washed in ice cold PBS, and fixed for 4 hours in 4\% PFA at 4

${ }^{\circ} \mathrm{C}$. The tissue was then incubated in 30\% sucrose overnight and frozen in OCT. $10 \mu \mathrm{m}$ cryosections were taken and placed on Superfrost Plus slides (Fisher Scientific). Immunohistochemistry for PLA2G6 was performed using the Mouse on Mouse kit (Vector Labs) and the Vectastain ABC HRP kit (Vector Labs).

\section{Mass spectrometry imaging analysis}

Nanospray desorption electrospray ionization (nano-DESI) mass spectrometry imaging was performed on a Q Exactive HF-X mass spectrometer (Thermo Fisher Scientific) (Yin et al., 2019). High-resolution nano-DESI probes were assembled using two fused silica capillaries pulled to O.D. 15- $25 \mu \mathrm{m}$. A shear force probe with a tip diameter of $\sim 10 \mu \mathrm{m}$ was integrated with the nano-DESI probe and was used to precisely control the distance between the probe and the sample. The position of the samples was controlled by a motorized $X Y Z$ stage. Samples were scanned at a rate of $10 \mu \mathrm{m} / \mathrm{s}$ under the nano-DESI probe in lines with a step of $20 \mu \mathrm{m}$ between the lines. A 9/1 (v/v) methanol/water mixture containing 200 nM LPC 19:0 (internal standard) was propelled through the nano-DESI probe at $500 \mathrm{~nL} / \mathrm{min}$ (see Supplementary Table 2 for parameters). A custom-designed software, MSI QuickView, was used for data visualization and processing. Ion images were generated by normalizing the signal of the analyte to the signal of the internal standard (LPC 19:0). Lipids were identified by matching based on the high mass accuracy against the species characterized in the lipidomics analysis.

\section{Fluorescence in-situ hybridization (FISH)}

FISH experiments were performed as previously described (Cui et al., 2018). Ten oligonucleotide probes containing targeting and 3' readout overhang domains were 
designed against the Pla2g6 transcript coding region (see Supplementary Table 3 for sequences). Each targeting domain was 20-nt long and complementary to the Pla2g6 mRNA, with CG content of $40-60 \%$, no self-repeats and inner loop structures. A secondary probe labeled with two Alexa647 molecules was used to hybridize with the 3' overhang domain. Samples were fixed with fresh 4\% paraformaldehyde. After quenching the residual paraformaldehyde was with $0.1 \%$ sodium borohydride, samples were permeabilized with $0.2 \%$ Triton-X 100 and stored in $70 \%$ ethanol. The primary and secondary probes (50 nM final concentration) and anti-insulin antibody (Supplementary Table 3) (1000-fold dilution) were diluted in hybridization solution (10\% dextran sulfate, 15\% formamide, $1 \times \mathrm{SSC}, 3.4 \mathrm{mg} / \mathrm{mL}$ tRNA, $0.2 \mathrm{mg} / \mathrm{mL}$ RNase-free BSA, $2 \mathrm{mM}$ ribonucleoside vanadyl complex) and incubated with the samples $37^{\circ} \mathrm{C}$ overnight in a humid chamber. Samples were rinsed with $15 \%$ formamide in $1 \times$ SSC, followed by staining with Atto 488-conjugated secondary antibody (Supplementary Table 3) and DAPI. Images were collected on an Olympus IX71-based single-molecule microscope equipped with $405 \mathrm{~nm}, 488 \mathrm{~nm}$, and $640 \mathrm{~nm}$ solid lasers. Images were captured using a 100× oil immersion objective lens (NA 1.4) and an EMCCD camera (Andor iXon Ultra 897). Fluctuation localization imaging-based FISH (fliFISH) was used to extract the true location of Pla2g6 mRNA in tissue sections to account for the background noise (Cui et al., 2018). The location for each Pla2g6 transcript was so calculated based on the center of mass. Photoswitching was activated by using GLOX-containing buffer: 50 mM Tris, 10 $\mathrm{mM} \mathrm{NaCl}, 10 \%$ glucose, $560 \mu \mathrm{g} / \mathrm{mL}$ glucose oxidase, $34 \mu \mathrm{g} / \mathrm{mL}$ catalase and $1 \% \beta$ mercaptoethanol.

\section{Quantitative real-time PCR analysis}


Cells were harvested and total mRNA was extracted using the RNeasy Mini kit (Qiagen). cDNA synthesis was performed using the iScript synthesis kit (Biorad) and qRT-PCR assays were performed using SsoAdvanced Universal SYBR Green Supermix. Expression levels were normalized to the housekeeping gene GAPDH and quantified using the delta CT method (see Supplementary Table 3 for oligonucleotide information).

\section{Western Blotting}

Cells were harvested in RIPA buffer containing protease inhibitors and proteins were electrophoresed and transferred to PVDF membranes. After blocking in 5\% milk in TBS containing $0.1 \%$ Tween 20 , membranes were incubated in specific primary antibodies at $4^{\circ} \mathrm{C}$ overnight. Anti-mouse and anti-rabbit horseradish peroxidase-conjugated antibodies (Supplementary Table 3) were used for secondary antibodies and enhanced chemiluminescent substrate was used for signal detection.

\section{RESULTS}

\section{Lipidome analysis of $\beta$-cell death/type 1 diabetes models}

We studied three models of insulitis and T1D progression: (I) Human EndoC- $\beta \mathrm{H} 1$ cells exposed to the cytokines IL-1 $\beta+$ INF-y for $48 \mathrm{~h}$, (II) human islets exposed to the same cytokines for $24 \mathrm{~h}$, and (III) islets from non-obese diabetic (NOD) mice at the prediabetic stage (6-week old) vs. age-matched NOR mice. To verify that under the present experimental conditions 6 weeks corresponds to the initial T1D developmental stages of NOD mice, we performed proteomics analysis of islets from both NOD and NOR mice (Supplementary Table 4-5) and compared the results against published proteomics data of EndoC- $\beta \mathrm{H} 1$ cells and human islets exposed IL-1 $\beta$ + INF-y (Nakayasu et al., 2020a; 
Ramos-Rodriguez et al., 2019). We observed an upregulation of inflammatory markers, such as the antigen transport protein Tap1, the transcription factor Stat1 and the interferon-induced guanylate-binding protein GBP2 (Supplementary Figure 1). None of the samples had reduced levels of insulin (Supplementary Figure 1), confirming that the islets from 6-week old NOD mice already had evidence of inflammation but remained in a pre-diabetic stage without significant $\beta$-cell loss.

We next carried out lipidomics analysis of these samples, leading to the identification and quantification a total of 369, 558 and 251 lipid species in EndoC- $\beta \mathrm{H} 1$ cells, human islets and murine islets, respectively (Figure 1A, Supplementary Tables 6-11). A striking difference in the number of lysophospholipid species were observed comparing EndoC- $\beta \mathrm{H} 1$ cells with human or murine islets. Only 9 (2.4\% of the total) Iysophospholipid species were detected in EndoC- $\beta \mathrm{H} 1$ cells, compared to 89 (15.9\%) and $25(10.0 \%)$ in human and murine islets, respectively. To better understand possible lipid metabolic processes regulated in each of the models, we performed an enrichment analysis using Lipid Mini-On (Clair et al., 2019). This tool determines whether any specific lipid feature, such as head group, subclass, fatty acyl chain length or degree of unsaturation, is overrepresented among the differentially regulated lipids. In EndoC- $\beta \mathrm{H} 1$ cells, phosphatidylglycerol (PG), plasmanyl-phosphatidylethanolamine and lipids with polyunsaturated fatty acyl chains were enriched among the species regulated by the IL$1 \beta+$ INF-y treatment (Figure 1B). Similarly, lipids with polyunsaturated fatty acyl chains were also enriched in human islets treated with the cytokines (Figure 1B). In murine islets, only triacylglycerols (TG) with 58 total carbons in the fatty acyl chains were found to be significantly enriched (Figure 1B). 
We reasoned that lipid groups regulated in a coordinated/common fashion in EndoC- $\beta \mathrm{H} 1$ cells, human islets, and murine islets in response to proinflammatory cytokines were likely to be important for T1D pathogenesis (highlighted by stars in Figure 1A). Interestingly, LPC species, PC species with long, polyunsaturated fatty acyl chains, and TGs were commonly regulated across all three models; LPCs and PCs with long, polyunsaturated fatty acids were also upregulated, whereas TGs were consistently downregulated in all 3 sample types (Figure 2).

\section{Spatial distribution of coordinately regulated lipids in islets}

We further surmised that coordinately regulated lipids that were particularly important for T1D pathogenesis would be preferentially localized to islets. To test this hypothesis, we determined the spatial distribution of the commonly regulated lipid species in murine pancreas using mass spectrometry imaging (MSI). MSI analysis showed that several LPC species are preferentially localized to islets of both NOD and NOR mice, including LPC(18:0) and LPC(18:1), whereas species such as LPC(18:2) and LPC(16:0) had similar abundance compared to surrounding tissue (Figure $\mathbf{3 A - C}$ ). In contrast, LPC(20:4) seemed to be enriched in islets of NOR mice, while this same lipid species was depleted in islets from NOD mice (Figure 3A-C). As a control, the standard LPC(19:0), which is delivered with the extraction solvent, was evenly distributed throughout the tissue (Figure 3A). Similarly, the endogenous metabolite glycerophosphocholine (GPC) was also evenly distributed throughout the tissue (Figure 3A), which indicates an insignificant matrix effect (Lanekoff et al., 2014). As expected, several PC species including PC(34:1) and PC(36:2) displayed an even distribution between the islets and the surrounding tissue in both mouse strains (Figure $3 B-C$ ). 
Conversely, species with longer and polyunsaturated fatty acyl chains PC(40:5) and PC(40:6) were clearly enriched in islets from both NOR and NOD mice (Figure 3B-C). Unfortunately, the solvent composition used in imaging experiments did not allow us to analyze TG localization, due to inefficient extraction of this lipid class into 9:1 methanol:water mixture.

LPCs are generated by the release of fatty acid chains from phospholipids, a reaction catalyzed by phospholipases, such as the calcium-independent phospholipase A2 (iPLA2b/PLA2G6). Consistent with the localization of LPCs, Pla2g6 was also enriched in islets as demonstrated by combining fluorescent in situ hybridization (FISH) and immunohistochemistry (Figure 4A-B). Taken together these data support the notion that the generation of LPCs is mediated by phospholipases, such as Pla2g6, which is enriched in islets compared to the surrounding tissue.

\section{Pla2g6-dependent cytokine regulation in MIN6 cells}

To study the molecular mechanism(s) underlying phospholipase PLA2G6-mediated signaling in cytokine-exposed islets, we treated control and Pla2g6 knockdown (KD) MIN6 $\beta$ cells with IL-1 $\beta+$ INF-y + TNF $\alpha$ for $24 h$, followed by LC-MS/MS-based proteomics analysis. The cytokine treatment led to changes in abundance of 1043 out of the 5212 identified and quantified proteins (Figure 5A, Supplementary Table 12). A functionenrichment analysis of the differentially regulated proteins revealed that 52 KEGG pathways were regulated by the cytokine treatment (Figure 5B). Only a small fraction of 35 proteins that were differentially regulated by cytokines was dependent on PLA2G6 (Figure 5C, Supplementary Table 13). Among these proteins, the expression of cathepsin $\mathrm{Z}$ and cathepsin B were upregulated with the cytokine treatment, but this 
increase in abundance was abolished in the absence of PLA2G6 (Figures 5D-E). Cathepsins are markers of lysosomal function and autophagy, indicating a possible link between cytokine signaling and these processes through PLA2G6. As a control, we checked the expression levels of insulin-1 and insulin-2 proteins, but they were not affected by the Pla2g6 KD (Figure 5F-G). Overall, the analysis showed a strong regulation of the MIN6 $\beta$ cell proteome by pro-inflammatory cytokines, of which a small subset of proteins was dependent of PLA2G6.

\section{Regulation of poly(ADP)ribosylation proteins in MIN6 $\beta$ cells}

Among the PLA2G6-dependent cytokine-regulated proteins as judged by LC-MS proteomics was ADP-ribosyl-acceptor glycohydrolase ARH3 (ADPRHL2 gene) (Figure 5C). ARH3 has been shown to play a role in poly-ADP-ribose (PAR) metabolism, a factor that regulates $\beta$-cell death in mice (Andreone et al., 2012). We investigated the abundance profiles of the PAR polymerases (PARP) and hydrolases PAR glycohydrolases (PARG), MacroD1, MacroD2, terminal ADP-ribose protein glycohydrolase 1 (TARG1) and ADP-ribosyl-acceptor hydrolases (ARHs) in the proteomic analysis. PARP-1 abundance decreased approximately 35\% in both Pla2g6-KD and control cells when treated with cytokines, whereas PARP-2 was not significantly changed (Table 1). Conversely, PARP-3, $-9,-10,-12$ and -14 were strongly upregulated ( $>5$ fold) when cells were treated with cytokines in both wild-type and Pla2g6-KD cells (Table 1). The PAR hydrolases ARH3 and MacroD1 were also increased by $66 \%$ and $31 \%$, respectively, in the wild-type cells treated with cytokines, but their expression was unchanged in Pla2g6-KD cells treated with cytokines (Table 1). The other PAR hydrolases were not detected in our analysis. 
To further investigate the role of $\mathrm{ARH} 3$ in $\beta$-cell stress, we tested the effects of ARH3 KD in cytokine-mediated apoptosis by performing western blots of the apoptotic marker cleaved caspase 3. The KD reduced ARH3 protein levels by 65-72\% (Figure 6AB). The cytokine cocktail IL-1 $\beta+$ INF- $\gamma+$ TNF $\alpha$ increased the expression level of cleaved caspase 3 by 8.8 fold in the scramble RNAi cells as compared to the non-cytokine treated control group (Figure 6A and 6C). In ARH3 KD cells, the levels of cleaved caspase 3 were further increased by 15.4 fold (Figure 6A and 6C). Of note, ARH3 KD already had a higher basal level of cleaved caspase 3 (Figure 6A and 6C).

To gain more mechanistic insights, we performed proteomic analysis of the same samples (Supplementary Tables 14-15), which confirmed the reduction in ARH3 expression in the KD cells (Figure 6D). The levels of the pro-apoptotic Bcl-2 protein Bad and programmed cell death protein $4(\mathrm{Pdcd} 4)$ were reduced by the cytokine treatment and the ARH3 KD further reduced their levels (Figure 6E-F). Conversely, Parp12 levels increased with the cytokine treatment, but the ARH3 KD reduced this upregulation (Figure 6G). Parp12 was the only PARP regulated by cytokines in a PLA2G6-dependent fashion (Table 1), and since it was regulated in opposite direction in ARH3 KD it could represent a negative feedback mechanism. A function-enrichment analysis of the proteomics data showed that pathways such as antigen processing and presentation, and chemokine signaling, were regulated by cytokines and ARH3 (Supplementary Table 16). In terms of antigen processing and presentation, the antigen transporter protein Tap2, major histocompatibility complex I subunit H2-K1 and immunoproteasome subunit Psmb8 were consistently reduced in ARH3 KD cells as compared to scramble RNAi when cells were treated with cytokines (Figure $6 \mathrm{H}-\mathbf{J})$. Among the chemokine-regulating proteins, the 
transcription regulators Stat1 and Stat3 had both a minor (12\%) reduction in ARH3 KD cells treated with cytokines as compared to the scramble RNAi cells (Figure 6K-L). Conversely, the ARH3 KD enhanced the expression of some cytokine-induced genes, such as the chemokines $\mathrm{Ccl} 2$ and $\mathrm{Cxcl9}$, and nitric oxide synthase Nos2 (Figure 6M-O). We also observed that ARH3 KD reduced the abundance of lipid-related proteins, such as lysophosphatidylcholine acyltransferase Lpcat1, phospholipid scrambalase Plscr1 and serine palmitoyltransferase Sptlc1 (Figure 6P-R), suggesting a role of ARH3 in regulating lipid metabolism. Together, these data show a strong regulation of the poly(ADP)ribosylation machinery by cytokines in MIN6 $\beta$ cells and suggest that ARH3 is further regulated by PLA2G6, leading to $\beta$ cell protection from apoptosis through a complex regulatory network.

\section{DISCUSSION}

We investigated the remodeling of islet and $\beta$ cell lipid composition in 3 models of T1D. Since phenotypes found in model systems do not always reflect the physiology of disease, we performed lipidomic analysis across three different models type 1 diabetes: EndoC- $\beta \mathrm{H} 1$ cells exposed to the cytokines IL-1 $\beta+$ INF- $\gamma$, human islets exposed to the same cytokines and islets from non-obese diabetic (NOD) mice at the pre-diabetic stage. This analysis identified consistent changes in composition of specific classes of lipids: down regulation of TGs and upregulation of LPCs and PCs with long unsaturated fatty acid chains. TGs have been shown to be down-regulated in rat $\beta$ cells by the proinflammatory cytokine combination IL-1 $\beta+$ INF- $\gamma+T N F \alpha$, likely to accommodate the 
resulting increased energetic demands (Kiely et al., 2007). TG metabolism has also been associated with cellular protection; it has been shown that GDF15 impairs inflammationinduced damage by systemic release of liver TGs (Luan et al., 2019). Consistently, TGcarrying protein apolipoprotein CIII reduces apoptosis in rodent $\beta$ cells treated with IL-1 $\beta$ + INF-Y (Storling et al., 2011). Also, increases in cellular TG content has been associated with protection of rat $\beta$ cells against the cytotoxic effects of saturated free fatty acids (Cnop et al., 2001).

Our three different models of T1D also showed a consistent upregulation in the levels of PCs with long polyunsaturated fatty acid chains. Like TGs, polyunsaturated fatty acids have been associated with protection of $\beta$ cells against pro-inflammatory cytokines (Wei et al., 2010). An omega 3 polyunsaturated fatty acid diet reduces the incidence of diabetes in NOD mice (Bi et al., 2017). Polyunsaturated fatty acids are sources for immunomediators such as prostaglandins, leukotrienes and thromboxanes. While some of these immunomediators are anti-inflammatory, others induce inflammation and apoptosis. For instance, the processing of the polyunsaturated fatty acid arachidonic acid into 12-HETE by 12-lipoxygenase has been shown to lead to $\beta$-cell death (Tersey et al., 2015).

Polyunsaturated fatty acids are often associated with phospholipids but can be released from them by phospholipases. Multiple phospholipases may contribute to this process as we detected dozens of lipases in the proteomic analysis (Supplementary Tables 4, 12 and 14). We focused in the inducible phospholipase A2 beta (iPLA2b/PLA2G6) as it has been reported to regulated by cytokines in islets, releasing of polyunsaturated fatty acids and LPCs (Lei et al., 2014; Lei et al., 2010). This is in line with 
our results showing an accordant increase of LPCs in each of the T1D models. We also showed that several LPCs are enriched in islets, which is consistent with the observation that PLA2G6 expression is higher in islets compared to surrounding tissue. Our previous proteomics analysis showed that PLA2G6 is also expressed in human islets (Nakayasu et al., 2020a), while a previous report showed that its transcript is higher in rat $\beta$ cells compared to a cells (Ma et al., 1998). PLA2G6 has been shown to activate apoptosis via downstream activation of neutral sphingomyelinase and formation of ceramides, leading to mitochondrial membrane decompensation (Lei et al., 2014). Pharmacological inhibition of PLA2G6 protects NOD mice from developing diabetes (Bone et al., 2015). PLA2G6 can also induce alternative splicing and reduce the levels of the antiapoptotic protein Bcl$x(L)$ via neutral sphingomyelinase activation, ceramide production and ER stress (Barbour et al., 2015). We found upregulated species of ceramides in all three different models of T1D used (Figure 1). However, the IL-1 $\beta+$ INF- $\gamma$ treatment also downregulated the concentration of several ceramide species in human islets but not in the other 2 studied models (Figure 1), suggesting that additional processes might occur in human islets. PLA2G6 was previously shown to regulate autophagy and apoptosis in murine islets treated with the ER stressor, thapsigargin (Lei et al., 2013). This observation agrees with our proteomics data, which shows that PLA2G6 regulates lysosomal trafficking and autophagy markers cathepsin B and Z. Of note, another cathepsin, cathepsin $\mathrm{H}$, is a candidate gene for type 1 diabetes with a key role for $\beta$-cell function and survival (Floyel et al., 2014) and crinosomes, a cell structure that plays a key role for the generation of autoimmune peptides in diabetes prone NOD-mice (Wan et al., 2020), are rich in cathepsins. 
Here we show that PLA2G6 also regulates antiapoptotic signals by inducing the expression of the ADP-ribosyl-acceptor glycohydrolase ARH3. ARH3 hydrolyzes PAR from serine residues, counterbalancing the pro-apoptotic activity induced by ADP-ribose polymerization in oxidative stress (Abplanalp et al., 2017; Fontana et al., 2017; Mashimo et al., 2019). The molecular regulation of ARH3 is virtually unknown. PLA2 products, such as LPC and arachidonic acid induce signal transduction that activates the transcription factors NF-kB and AP-1, respectively (Becuwe et al., 2003; Carneiro et al., 2013). However, their role in regulating ARH3 is being pursued in ongoing studies.

In murine islets, PARP-1 has been shown to be involved in cytokine mediated $\beta$ cell death and PARP-1 deletion has been shown to protect against streptozotocinmediated diabetes (Andreone et al., 2012; Burkart et al., 1999; Masutani et al., 1999). Our data show that this scenario might be more complex as PARP-3, $-9,-10,-12$ and -14 are strongly upregulated in cells treated with the cytokines IL-1 $1 \beta+$ INF- $\gamma+$ TNF $\alpha$, but their role in $\beta$-cell death still needs to be investigated. Of these PARPs, we found that PARP12 expression was induced by cytokines. However, while the PLAG2G6 KD further increased the PARP-12 levels, the ARH3 KD reduced its abundance, which may represent a negative feedback mechanism. ARH3 KD further the cytokine-mediated downregulation of the apoptosis related proteins Bad and Pdcd4. ARH3 KD decreased the expression levels of proteins involved in antigen processing and presentation, a process tightly related to the development of autoimmunity and T1D (DiMeglio et al., 2018). Conversely, ARH3 KD increased the abundance of the pro-inflammatory cytokineinduced proteins, such as Nos2 (Suarez-Pinzon et al., 2001), and the chemokines Ccl2 and Cxcl9 (Karin et al., 2016), while decreasing the expression of lysophosphatidylcholine 
acetyltransferase Lpcat1, phospholipid scrambalase Plscr1 and serine palmitoyltransferase Sptlc1. The regulation of Lpcat1, Plscr1 and Sptlc1 proteins by ARH3 suggests that it may contribute to maintaining lipid homeostasis. Intriguingly, all these proteins have been previously shown to have pro- or anti-apoptotic functions and/or to contribute to T1D development (Akagi et al., 2016; Karin et al., 2016; Ramos-Rodriguez et al., 2019; Sivagnanam et al., 2017; Suarez-Pinzon et al., 2001; Taouji et al., 2013). Therefore, our data suggest that ARH3 promotes $\beta$-cell survival by balancing pro- and anti-apoptotic factors through a very complex regulatory network (Figure 7).

Overall, our data showed a consistent regulation of the lipid metabolism in 3 different models of insulitis. Additionally, we demonstrated that phospholipase Pla2g6 signaling leads to the upregulation of $\mathrm{ARH} 3$ which triggers a complex regulatory network that provides a feedback mechanism that reduces apoptosis.

\section{Acknowledgements}

The authors thank the NIDDK-supported Integrated Islet Distribution Program (IIDP) for providing the human islets used in the study. Work was performed in the Environmental Molecular Sciences Laboratory, a U.S. Department of Energy (DOE) national scientific user facility at Pacific Northwest National Laboratory (PNNL) in Richland, WA. Battelle operates PNNL for the DOE under contract DE-AC05-76RLO01830. A non-peer reviewed, preprint version of this work was uploaded into Biorxiv under DOI: https://doi.org/10.1101/2020.03.23.004481.

\section{Funding}

This work was supported by National Institutes of Health, National Institute of Diabetes and Digestive and Kidney Diseases grants UC4 DK108101 (to C.A. and L.S.), UC4 
DK104166 (to R.G.M, C.E. M., D.L.E, and T.O.M.), U01 DK127786 (to R.G.M, C.E. M., D.L.E, B.J.M.W.R and T.O.M.), R01 DK105588 (to R.G.M.) and R01 DK093954 (to C.E.M); VA Merit Award I01BX001733 (to C.E.M.); Fonds National de la Recherche Scientifique (FNRS), Welbio CR-2015A-06, Belgium (to D.L.E.); a JDRF Strategic Research Agreement (to C.E.M and R.G.M.) and gifts from the Sigma Beta Sorority, the Ball Brothers Foundation, the George and Frances Ball Foundation, and the Holiday Management Foundation (to C.E.M and R.G.M.). F.S. was supported by JDRF postdoctoral fellowship (3-PDF-2016-199-A-N). D.L.E. also received funds from Innovative Medicines Initiative 2 Joint Undertaking under grant agreement No 115797 (INNODIA), which is supported by the Union's Horizon 2020 research and innovation program and EFPIA, JDRF and The Leona M. and Harry B. Helmsley Charitable Trust.

\section{Competing interests}

The authors declare that they have no competing interests.

\section{Authors' contributions}

E.S.N., L.S., C.A. conceived the study and participated in the study design. E.S.N., M.G., J.K., D.S., C.D., R.Y., Y.C., C.N., F.S., and J.J.M. performed the experiments. All the authors performed the data analysis. E.S.N., R.Y., Y.C., B.J.W.R., J.L., L.S. and C.A. wrote the manuscript. All authors read, revised and approved the final manuscript for publication.

\section{Data and Resource Availability}

Proteomics data were deposited into Pride repository (www.ebi.ac.uk/pride) under accession number PXD017863, PXD021501 and PXD021475. Lipidomics data were deposited into Massive repository (http://massive.ucsd.edu/) under accession number MSV000086174.

Pla2g6-dependent cytokine signaling in MIN6 cells

Project number: PXD017863

Reviewer account details:

Username: reviewer04836@ebi.ac.uk

Password: B401VcPd 
ARH3-regulated cytokine signaling in MIN6 cells

Project accession: PXD021501

Reviewer account details:

Username: reviewer_pxd021501@ebi.ac.uk

Password: NbhKnd9N

Proteomics analysis of islets of 6-week old NOR and NOD mice

Project accession: PXD021475

Reviewer account details:

Username: reviewer_pxd021475@ebi.ac.uk

Password: tKFfLzrh

Lipidomics of 3 models of insulitis, beta-cell stress and type 1 diabetes development Project accession: MSV000086174

Reviewer account details:

Username: MSV000086174_reviewer

Password: Islets3663 
Table 1 - Abundance profiles of poly(ADP)ribosylation proteins in wild-type and Pla2g6 knockdown MIN6 $\beta$ cells treated with the pro-inflammatory cytokines. ${ }^{\mathrm{i}} \mathrm{BAQ}$ - intensity-based absolute quantification. Statistical test was done with $t$-test considering equal variation and distribution.

\begin{tabular}{|c|c|c|c|c|c|c|c|c|c|c|c|c|c|}
\hline \multirow[b]{3}{*}{$\begin{array}{l}\text { Accession } \\
\text { number }\end{array}$} & \multirow[b]{3}{*}{ Protein } & \multicolumn{4}{|c|}{ Average iBAQ intensity } & \multicolumn{4}{|c|}{ Standard deviation } & & & & \\
\hline & & \multicolumn{2}{|l|}{ Wild type } & \multicolumn{2}{|c|}{ Pla2g6 RNAi } & \multicolumn{2}{|l|}{ Wild type } & \multicolumn{2}{|c|}{\begin{tabular}{|l|} 
Pla2g6-RNAi \\
\end{tabular}} & \multicolumn{2}{|c|}{$\begin{array}{l}\text { Fold change } \\
\text { (Treated/Control) }\end{array}$} & \multicolumn{2}{|c|}{$\begin{array}{l}\text { p-value (Control } \\
\text { vs. treated) }\end{array}$} \\
\hline & & Control & Treated & Control & Treated & Control & Treated & Control & Treated & $\begin{array}{l}\text { Wild } \\
\text { type }\end{array}$ & $\begin{array}{l}\text { Pla2g6 } \\
\text { RNAi }\end{array}$ & $\begin{array}{l}\text { Wild } \\
\text { type }\end{array}$ & $\begin{array}{l}\text { Pla2g6 } \\
\text { RNAi }\end{array}$ \\
\hline Q921K2 & PARP-1 & 160541298 & 102181010 & 162185126 & 98199854 & 14415018 & 13769483 & 11315442 & 11911652 & 0.64 & 0.61 & 0.000 & 0.000 \\
\hline O88554 & PARP-2 & 2320187 & 1886698 & 2701832 & 1904552 & 773539 & 900914 & 606622 & 619003 & 0.81 & 0.70 & 0.438 & 0.074 \\
\hline Q8CFB8 & PARP-3 & 0 & 2440297 & 129711 & 2796473 & 0 & 1950741 & 290043 & 1320074 & $\infty$ & 21.56 & 0.023 & 0.002 \\
\hline Q8CAS9 & PARP-9 & 1027221 & 39521623 & 1758362 & 44078979 & 833995 & 6228610 & 1232660 & 4239980 & 38.47 & 25.07 & 0.000 & 0.000 \\
\hline Q8CIE4 & PARP-10 & 100029 & 4173449 & 93000 & 4561784 & 223672 & 1064209 & 207955 & 1039258 & 41.72 & 49.05 & 0.000 & 0.000 \\
\hline Q8BZ20 & PARP-12 & 613429 & 3541763 & 861360 & 6368375 & 261033 & 682862 & 471954 & 1427301 & 5.77 & 7.39 & 0.000 & 0.000 \\
\hline Q2EMV9 & PARP-14 & 616310 & 26623139 & 769444 & 27348827 & 84838 & 2863548 & 321341 & 1432066 & 43.20 & 35.54 & 0.000 & 0.000 \\
\hline Q8CG72 & ARH3 & 11541195 & 19182811 & 11421375 & 12104702 & 3610258 & 2655778 & 3105854 & 1940956 & 1.66 & 1.06 & 0.005 & 0.688 \\
\hline Q922B1 & MacroD1 & 16322818 & 21400784 & 19062601 & 17347089 & 3285980 & 2286317 & 3446722 & 3884448 & 1.31 & 0.91 & 0.022 & 0.481 \\
\hline
\end{tabular}




\section{Legends:}

Figure 1. Global lipidomic analysis of 3 common models used for the study of $\beta$-cell stress in type 1 diabetes: (I) EndoC- $\beta \mathrm{H} 1$ cells exposed to IL-1 $\beta$ and INF- $\gamma$ for $48 \mathrm{~h}(\mathrm{n}=3)$, (II) human islets exposed to same cytokines for $24 \mathrm{~h}(\mathrm{n}=10)$ and (III) islets from non-obese diabetic (NOD) mice in pre-diabetic stage (6 weeks of age) vs. age-matched NOR mice $(n=3)$. Lipids were extracted and analyzed by liquid chromatography-tandem mass spectrometry. (A) Number of identified and regulated species in lipid subclass. (B) Lipid features and groups that were significantly enriched ( $p \leq 0.05$, Fisher's exact test) among the differentially regulated species. *Lipid classes consistently regulated in all three samples.

Figure 2. Lipid species that are consistently regulated in 3 models of $\beta$-cell stress in type 1 diabetes. Lipids from EndoC- $\beta \mathrm{H} 1$ cells treated with IL-1 $\beta$ and INF- $\gamma$ for $48 \mathrm{~h}$, human islets treated with the proinflammatory cytokines IL-1 $\beta$ and INF- $\gamma$ for $24 \mathrm{~h}$ and islets from non-obese diabetic (NOD) mice in pre-diabetic stage (6 weeks of age) were extracted and analyzed by liquid chromatography tandem mass spectrometry. Each lipid species is named with the abbreviation of its class (e.g. LPC and PC) followed by the length of the fatty acid and number of double bounds (separated by colon) in parenthesis. The letters after the lipid names represent different isomers that are separated in the chromatography in alphabetical order. The relative abundance in T1D model vs. control are color-coded. Isobaric coeluting species (separated by semicolons) were co-quantified.

Figure 3. Spatial localization of lysophosphatidylcholine (LPC) and phosphatidylcholine (PC) species in pancreata from NOR (A and B) or NOD mice (C) by mass spectrometry imaging. Each image shows either the optical image or color-coded distribution of different lipid, endogenous metabolite [glycerophosphocoline (GPC)] and standard [LPC(19:0)] species. Each lipid species is named with the abbreviation of its class (e.g. LPC and PC) followed by the length of the fatty acid chains and number of double bounds (separated by colon) in parenthesis. Pancreata from 6-week old mice were collected and analyzed in independent experiments. Lipid species were identified by matching against the lipids characterized on the lipidomics analysis based on their accurate masses.

Figure 4. Pla2g6 distribution. (A) Fluorescence in situ hybridization (FISH) of MIN6 $\beta$ cell line, and pancreata from non-obese diabetic (NOD) and non-obese diabetes resistant (NOR) mice ( 6 weeks of age). Cells and tissues were stained with anti-insulin antibody (green), DNA stain 4',6-diamidino-2-phenylindole (DAPI - blue) and fluorescent-labeled antisense Pla2g6 oligonucleotide (red). (B) Immunohistochemistry (IHC) analysis of Pla2g6. Tissue was stained with biotin-conjugated anti-Pla2g6 antibodies followed by avidin-conjugated horseradish peroxidase. Localization was visualized by horseradish peroxidase-mediated oxidation and precipitation of 3,3'-diaminobenzidine (brown). 
Figure 5. Pro-inflammatory cytokines IL-1 $\beta$ + IFN-y + TNF $\alpha$ and Pla2g6-dependent proteome remodeling in MIN6 $\beta$ cells. (A) Pro-inflammatory cytokines (Cyt)-dependent protein expression in wild-type (WT) and Pla2g6-RNAi MIN6 cells ( $n=5$, each). (B) KEGG pathways enriched with proteins differentially abundant in IL-1 $\beta$ + IFN- $\gamma$-treated MIN6 cells. Pathways were grouped based on shared proteins using Enrichment Map (Merico et al., 2010). Each pathway is represented by a node and their degree of connectivity (thickness of the edges) is proportional to the number of shared proteins between the pathways. (C) Pla2g6-dependent protein abundance changes of pro-inflammatory cytokine-treated MIN6 cells. (D-G) Abundance profiles of cathepsin Z (D), cathepsin B $(E)$, insulin-1 (F) and insulin-2 (G). Statistical test: ** $p \leq 0.01$ and ${ }^{* * *} p \leq 0.001$ by $t$-test considering equal distribution and variance.

Figure 6. The role of ADP-ribosy-acceptor glycohydrolase ARH3 in cytokine-signaling of MIN $6 \beta$ cells. MIN6 cells were transfected with ARH3 RNAi or scrambled oligonucleotides and treated with $100 \mathrm{ng} / \mathrm{mL}$ IFN- $\gamma, 10 \mathrm{ng} / \mathrm{mL}$ TNF- $\alpha$, and $5 \mathrm{ng} / \mathrm{mL} \mathrm{IL}-1 \beta$ for $24 \mathrm{~h}$ and then analyzed by western blot and proteomics analysis. (A) Western blot analysis of ARH3 KD cells treated with cytokines. (B-C) Quantification of the levels of ARH3 (B) and cleaved caspase 3 (C) bands. To ensure the reproducibility we performed experiment multiple times. The data is representative of 4 independent experiments and 6 replicates total with similar results. (D-R) Quantification of selected proteins from the proteomics analysis (Supplementary Tables 14-16): (D) ARH3, (E) Bad: Bcl2-associated agonist of cell death, (F) Pdcd4: Programmed cell death protein 4, (G) Parp12: Poly [ADP-ribose] polymerase 12, (H) Tap2: Antigen peptide transporter 2, (I) H2-K1: H-2 class I histocompatibility antigen K-B alpha chain, (J) Psmb8: Proteasome subunit beta type-8, (K) Stat1: Signal transducer and activator of transcription 1, (L) Stat3: Signal transducer and activator of transcription 3, (M) Ccl2: C-C motif chemokine 2, (N) Cxcl9: C-X-C motif chemokine 9, (O) Nos2: Inducible nitric oxide synthase, (P) Lpcat1: Lysophosphatidylcholine acyltransferase 1, (Q) Plscr1: Phospholipid scramblase 1, (R) Sptlc1: Serine palmitoyltransferase 1. Statistical test: * $p \leq 0.05,{ }^{* *} p \leq 0.01$ and ${ }^{* * *} p \leq 0.001$ by $t$-test considering equal distribution and variance.

Figure 7. Model of cytokine signaling regulated by phospholipase PLA2G6 and ADPribosyl-acceptor glycohydrolase ARH3. Cytokines activates PLA2G6 that induces an upregulation of ARH3. ARH3 in turn suppresses apoptosis and cytokine-induced genes, such as chemokines and nitric oxide synthase (Nos2). ARH3 also enhances the expression of genes related to antigen presentation and lipid metabolic proteins.

Supplementary Figure 1. Abundance of selected proteins from proteomics analysis of 3 common models used for the study of $\beta$-cell stress in type 1 diabetes: $(A)$ EndoC- $\beta \mathrm{H} 1$ 
cells exposed to IL-1 $\beta$ and INF-y for $48 \mathrm{~h}(\mathrm{n}=3)$ (Ramos-Rodriguez et al., 2019), (B) human islets exposed to same cytokines for $24 \mathrm{~h}(\mathrm{n}=10)$ (Nakayasu et al., 2020b) and (C) islets from non-obese diabetic (NOD) mice in pre-diabetic stage (6 weeks of age) vs. age-matched NOR mice $(n=3)$ (Supplementary Tables 4-5). Abbreviations: GBP2: interferon-induced guanylated-binding protein 2, Stat1: signal transducer and activator of transcription 1, TAP1: antigen peptide transporter 1 . Statistical test: ${ }^{* *} p \leq 0.01$ and ${ }^{* * *}$ $\mathrm{p} \leq 0.001$ by $t$-test considering equal distribution and variance. 


\section{References}

Abplanalp, J., Leutert, M., Frugier, E., Nowak, K., Feurer, R., Kato, J., Kistemaker, H.V.A., Filippov, D.V., Moss, J., Caflisch, A., et al. (2017). Proteomic analyses identify ARH3 as a serine mono-ADP-ribosylhydrolase. Nat Commun 8, 2055.

Akagi, S., Kono, N., Ariyama, H., Shindou, H., Shimizu, T., and Arai, H. (2016). Lysophosphatidylcholine acyltransferase 1 protects against cytotoxicity induced by polyunsaturated fatty acids. FASEB J 30, 2027-2039.

Andreone, T., Meares, G.P., Hughes, K.J., Hansen, P.A., and Corbett, J.A. (2012). Cytokine-mediated beta-cell damage in PARP-1-deficient islets. Am J Physiol Endocrinol Metab 303, E172-179.

Barbour, S.E., Nguyen, P.T., Park, M., Emani, B., Lei, X., Kambalapalli, M., Shultz, J.C., Wijesinghe, D., Chalfant, C.E., and Ramanadham, S. (2015). Group VIA Phospholipase A2 (iPLA2beta) Modulates Bcl-x 5'-Splice Site Selection and Suppresses Anti-apoptotic Bcl-x(L) in beta-Cells. J Biol Chem 290, 11021-11031.

Becuwe, P., Bianchi, A., Didelot, C., Barberi-Heyob, M., and Dauca, M. (2003). Arachidonic acid activates a functional AP-1 and an inactive NF-kappaB complex in human HepG2 hepatoma cells. Free Radic Biol Med 35, 636-647.

Beilke, J.N., Kuhl, N.R., Van Kaer, L., and Gill, R.G. (2005). NK cells promote islet allograft tolerance via a perforin-dependent mechanism. Nat Med 11, 1059-1065.

Bi, X., Li, F., Liu, S., Jin, Y., Zhang, X., Yang, T., Dai, Y., Li, X., and Zhao, A.Z. (2017). omega-3 polyunsaturated fatty acids ameliorate type 1 diabetes and autoimmunity. $\mathrm{J}$ Clin Invest 127, 1757-1771.

Bone, R.N., Gai, Y., Magrioti, V., Kokotou, M.G., Ali, T., Lei, X., Tse, H.M., Kokotos, G., and Ramanadham, S. (2015). Inhibition of Ca2+-independent phospholipase A2beta (iPLA2beta) ameliorates islet infiltration and incidence of diabetes in NOD mice. Diabetes 64, 541-554.

Burkart, V., Wang, Z.Q., Radons, J., Heller, B., Herceg, Z., Stingl, L., Wagner, E.F., and Kolb, H. (1999). Mice lacking the poly(ADP-ribose) polymerase gene are resistant to pancreatic beta-cell destruction and diabetes development induced by streptozocin. Nat Med 5, 314-319.

Carneiro, A.B., Iaciura, B.M., Nohara, L.L., Lopes, C.D., Veas, E.M., Mariano, V.S., Bozza, P.T., Lopes, U.G., Atella, G.C., Almeida, I.C., et al. (2013). Lysophosphatidylcholine triggers TLR2- and TLR4-mediated signaling pathways but counteracts LPS-induced NO synthesis in peritoneal macrophages by inhibiting NFkappaB translocation and MAPK/ERK phosphorylation. PLoS One 8, e76233.

Chambers, K.T., Weber, S.M., and Corbett, J.A. (2007). PGJ2-stimulated beta-cell apoptosis is associated with prolonged UPR activation. Am J Physiol Endocrinol Metab 292, E1052-1061.

Clair, G., Reehl, S., Stratton, K.G., Monroe, M.E., Tfaily, M.M., Ansong, C., and Kyle, J.E. (2019). Lipid Mini-On: mining and ontology tool for enrichment analysis of lipidomic data. Bioinformatics 35, 4507-4508.

Cnop, M., Hannaert, J.C., Hoorens, A., Eizirik, D.L., and Pipeleers, D.G. (2001). Inverse relationship between cytotoxicity of free fatty acids in pancreatic islet cells and cellular triglyceride accumulation. Diabetes 50, 1771-1777. 
Cox, J., and Mann, M. (2008). MaxQuant enables high peptide identification rates, individualized p.p.b.-range mass accuracies and proteome-wide protein quantification. Nat Biotechnol 26, 1367-1372.

Cui, Y., Hu, D., Markillie, L.M., Chrisler, W.B., Gaffrey, M.J., Ansong, C., Sussel, L., and Orr, G. (2018). Fluctuation localization imaging-based fluorescence in situ hybridization (fliFISH) for accurate detection and counting of RNA copies in single cells. Nucleic Acids Res 46, e7.

Dautel, S.E., Kyle, J.E., Clair, G., Sontag, R.L., Weitz, K.K., Shukla, A.K., Nguyen, S.N., Kim, Y.M., Zink, E.M., Luders, T., et al. (2017). Lipidomics reveals dramatic lipid compositional changes in the maturing postnatal lung. Sci Rep 7, 40555.

DiMeglio, L.A., Evans-Molina, C., and Oram, R.A. (2018). Type 1 diabetes. Lancet 391, 2449-2462.

Dobrian, A.D., Morris, M.A., Taylor-Fishwick, D.A., Holman, T.R., Imai, Y., Mirmira, R.G., and Nadler, J.L. (2019). Role of the 12-lipoxygenase pathway in diabetes pathogenesis and complications. Pharmacol Ther 195, 100-110.

Eizirik, D.L., Pasquali, L., and Cnop, M. (2020). Pancreatic beta-cells in type 1 and type 2 diabetes mellitus: different pathways to failure. Nat Rev Endocrinol 16, 349-362.

Floyel, T., Brorsson, C., Nielsen, L.B., Miani, M., Bang-Berthelsen, C.H., Friedrichsen, M., Overgaard, A.J., Berchtold, L.A., Wiberg, A., Poulsen, P., et al. (2014). CTSH regulates beta-cell function and disease progression in newly diagnosed type 1 diabetes patients. Proc Natl Acad Sci U S A 111, 10305-10310.

Fontana, P., Bonfiglio, J.J., Palazzo, L., Bartlett, E., Matic, I., and Ahel, I. (2017). Serine ADP-ribosylation reversal by the hydrolase ARH3. Elife 6.

Huang da, W., Sherman, B.T., and Lempicki, R.A. (2009). Systematic and integrative analysis of large gene lists using DAVID bioinformatics resources. Nat Protoc 4, 44-57.

Huo, L., Harding, J.L., Peeters, A., Shaw, J.E., and Magliano, D.J. (2016). Life expectancy of type 1 diabetic patients during 1997-2010: a national Australian registry-based cohort study. Diabetologia 59, 1177-1185.

Karin, N., Wildbaum, G., and Thelen, M. (2016). Biased signaling pathways via CXCR3 control the development and function of CD4+ T cell subsets. J Leukoc Biol 99, 857-862. Kiely, A., McClenaghan, N.H., Flatt, P.R., and Newsholme, P. (2007). Pro-inflammatory cytokines increase glucose, alanine and triacylglycerol utilization but inhibit insulin secretion in a clonal pancreatic beta-cell line. J Endocrinol 195, 113-123.

Lamichhane, S., Ahonen, L., Dyrlund, T.S., Kemppainen, E., Siljander, H., Hyoty, H., Ilonen, J., Toppari, J., Veijola, R., Hyotylainen, T., et al. (2018). Dynamics of Plasma Lipidome in Progression to Islet Autoimmunity and Type 1 Diabetes - Type 1 Diabetes Prediction and Prevention Study (DIPP). Sci Rep 8, 10635.

Lanekoff, I., Stevens, S.L., Stenzel-Poore, M.P., and Laskin, J. (2014). Matrix effects in biological mass spectrometry imaging: identification and compensation. Analyst 139, 3528-3532.

Lei, X., Bone, R.N., Ali, T., Wohltmann, M., Gai, Y., Goodwin, K.J., Bohrer, A.E., Turk, J., and Ramanadham, S. (2013). Genetic modulation of islet beta-cell iPLA(2)beta expression provides evidence for its impact on beta-cell apoptosis and autophagy. Islets 5, 29-44.

Lei, X., Bone, R.N., Ali, T., Zhang, S., Bohrer, A., Tse, H.M., Bidasee, K.R., and Ramanadham, S. (2014). Evidence of contribution of iPLA2beta-mediated events during 
islet beta-cell apoptosis due to proinflammatory cytokines suggests a role for iPLA2beta in T1D development. Endocrinology 155, 3352-3364.

Lei, X., Zhang, S., Emani, B., Barbour, S.E., and Ramanadham, S. (2010). A link between endoplasmic reticulum stress-induced beta-cell apoptosis and the group VIA Ca2+independent phospholipase A2 (iPLA2beta). Diabetes Obes Metab 12 Suppl 2, 93-98. Luan, H.H., Wang, A., Hilliard, B.K., Carvalho, F., Rosen, C.E., Ahasic, A.M., Herzog, E.L., Kang, I., Pisani, M.A., Yu, S., et al. (2019). GDF15 Is an Inflammation-Induced Central Mediator of Tissue Tolerance. Cell 178, 1231-1244 e1211.

Ma, Z., Ramanadham, S., Corbett, J.A., Bohrer, A., Gross, R.W., McDaniel, M.L., and Turk, J. (1996). Interleukin-1 enhances pancreatic islet arachidonic acid 12-lipoxygenase product generation by increasing substrate availability through a nitric oxide-dependent mechanism. J Biol Chem 271, 1029-1042.

Ma, Z., Ramanadham, S., Hu, Z., and Turk, J. (1998). Cloning and expression of a group IV cytosolic $\mathrm{Ca2+-dependent} \mathrm{phospholipase} \mathrm{A2} \mathrm{from} \mathrm{rat} \mathrm{pancreatic} \mathrm{islets.} \mathrm{Comparison} \mathrm{of}$ the expressed activity with that of an islet group VI cytosolic Ca2+-independent phospholipase A2. Biochim Biophys Acta 1391, 384-400.

Mashimo, M., Bu, X., Aoyama, K., Kato, J., Ishiwata-Endo, H., Stevens, L.A., Kasamatsu, A., Wolfe, L.A., Toro, C., Adams, D., et al. (2019). PARP1 inhibition alleviates injury in ARH3-deficient mice and human cells. JCI Insight 4.

Masutani, M., Suzuki, H., Kamada, N., Watanabe, M., Ueda, O., Nozaki, T., Jishage, K., Watanabe, T., Sugimoto, T., Nakagama, H., et al. (1999). Poly(ADP-ribose) polymerase gene disruption conferred mice resistant to streptozotocin-induced diabetes. Proc Natl Acad Sci U S A 96, 2301-2304.

Merico, D., Isserlin, R., Stueker, O., Emili, A., and Bader, G.D. (2010). Enrichment map: a network-based method for gene-set enrichment visualization and interpretation. PLoS One 5, e13984.

Nakayasu, E.S., Nicora, C.D., Sims, A.C., Burnum-Johnson, K.E., Kim, Y.M., Kyle, J.E., Matzke, M.M., Shukla, A.K., Chu, R.K., Schepmoes, A.A., et al. (2016). MPLEx: a Robust and Universal Protocol for Single-Sample Integrative Proteomic, Metabolomic, and Lipidomic Analyses. mSystems 1.

Nakayasu, E.S., Syed, F., Tersey, S.A., Gritsenko, M.A., Mitchell, H.D., Chan, C.Y., Dirice, E., Turatsinze, J.V., Cui, Y., Kulkarni, R.N., et al. (2020a). Comprehensive Proteomics Analysis of Stressed Human Islets Identifies GDF15 as a Target for Type 1 Diabetes Intervention. Cell Metab 31, 363-374 e366.

Nakayasu, E.S., Syed, F., Tersey, S.A., Gritsenko, M.A., Mitchell, H.D., Chan, C.Y., Dirice, E., Turatsinze, J.V., Cui, Y., Kulkarni, R.N., et al. (2020b). Comprehensive Proteomics Analysis of Stressed Human Islets Identifies GDF15 as a Target for Type 1 Diabetes Intervention. Cell Metab.

Oresic, M., Gopalacharyulu, P., Mykkanen, J., Lietzen, N., Makinen, M., Nygren, H., Simell, S., Simell, V., Hyoty, H., Veijola, R., et al. (2013). Cord serum lipidome in prediction of islet autoimmunity and type 1 diabetes. Diabetes 62, 3268-3274.

Pluskal, T., Castillo, S., Villar-Briones, A., and Oresic, M. (2010). MZmine 2: modular framework for processing, visualizing, and analyzing mass spectrometry-based molecular profile data. BMC Bioinformatics 11, 395. 
Polpitiya, A.D., Qian, W.J., Jaitly, N., Petyuk, V.A., Adkins, J.N., Camp, D.G., 2nd, Anderson, G.A., and Smith, R.D. (2008). DAnTE: a statistical tool for quantitative analysis of -omics data. Bioinformatics 24, 1556-1558.

Ramos-Rodriguez, M., Raurell-Vila, H., Colli, M.L., Alvelos, M.I., Subirana-Granes, M., Juan-Mateu, J., Norris, R., Turatsinze, J.V., Nakayasu, E.S., Webb-Robertson, B.M., et al. (2019). The impact of proinflammatory cytokines on the beta-cell regulatory landscape provides insights into the genetics of type 1 diabetes. Nat Genet 51, 1588-1595.

Schwanhausser, B., Busse, D., Li, N., Dittmar, G., Schuchhardt, J., Wolf, J., Chen, W., and Selbach, M. (2011). Global quantification of mammalian gene expression control. Nature 473, 337-342.

Sivagnanam, U., Palanirajan, S.K., and Gummadi, S.N. (2017). The role of human phospholipid scramblases in apoptosis: An overview. Biochim Biophys Acta Mol Cell Res 1864, 2261-2271.

Storling, J., Juntti-Berggren, L., Olivecrona, G., Prause, M.C., Berggren, P.O., and Mandrup-Poulsen, T. (2011). Apolipoprotein CIII reduces proinflammatory cytokineinduced apoptosis in rat pancreatic islets via the Akt prosurvival pathway. Endocrinology 152, 3040-3048.

Suarez-Pinzon, W.L., Mabley, J.G., Strynadka, K., Power, R.F., Szabo, C., and Rabinovitch, A. (2001). An inhibitor of inducible nitric oxide synthase and scavenger of peroxynitrite prevents diabetes development in NOD mice. J Autoimmun 16, 449-455.

Syed, I., Rubin de Celis, M.F., Mohan, J.F., Moraes-Vieira, P.M., Vijayakumar, A., Nelson, A.T., Siegel, D., Saghatelian, A., Mathis, D., and Kahn, B.B. (2019). PAHSAs attenuate immune responses and promote beta cell survival in autoimmune diabetic mice. J Clin Invest 129, 3717-3731.

Taouji, S., Higa, A., Delom, F., Palcy, S., Mahon, F.X., Pasquet, J.M., Bosse, R., Segui, B., and Chevet, E. (2013). Phosphorylation of serine palmitoyltransferase long chain-1 (SPTLC1) on tyrosine 164 inhibits its activity and promotes cell survival. J Biol Chem 288, 17190-17201.

Tersey, S.A., Bolanis, E., Holman, T.R., Maloney, D.J., Nadler, J.L., and Mirmira, R.G. (2015). Minireview: 12-Lipoxygenase and Islet beta-Cell Dysfunction in Diabetes. Mol Endocrinol 29, 791-800.

Verges, B. (2009). Lipid disorders in type 1 diabetes. Diabetes Metab 35, 353-360.

Wan, X., Vomund, A.N., Peterson, O.J., Chervonsky, A.V., Lichti, C.F., and Unanue, E.R. (2020). The MHC-II peptidome of pancreatic islets identifies key features of autoimmune peptides. Nat Immunol 21, 455-463.

Wei, D., Li, J., Shen, M., Jia, W., Chen, N., Chen, T., Su, D., Tian, H., Zheng, S., Dai, Y., et al. (2010). Cellular production of n-3 PUFAs and reduction of n-6-to-n-3 ratios in the pancreatic beta-cells and islets enhance insulin secretion and confer protection against cytokine-induced cell death. Diabetes 59, 471-478.

Yin, R., Burnum-Johnson, K.E., Sun, X., Dey, S.K., and Laskin, J. (2019). High spatial resolution imaging of biological tissues using nanospray desorption electrospray ionization mass spectrometry. Nat Protoc 14, 3445-3470. 
bioRxiv preprint doi: https://doi.org/10.1101/2020.03.23.004481; this version posted December 23, 2020. The copyright holder for this preprint (which was not certified by peer review) is the author/funder. All rights reserved. No reuse allowed without permission.

\section{Figure 1}

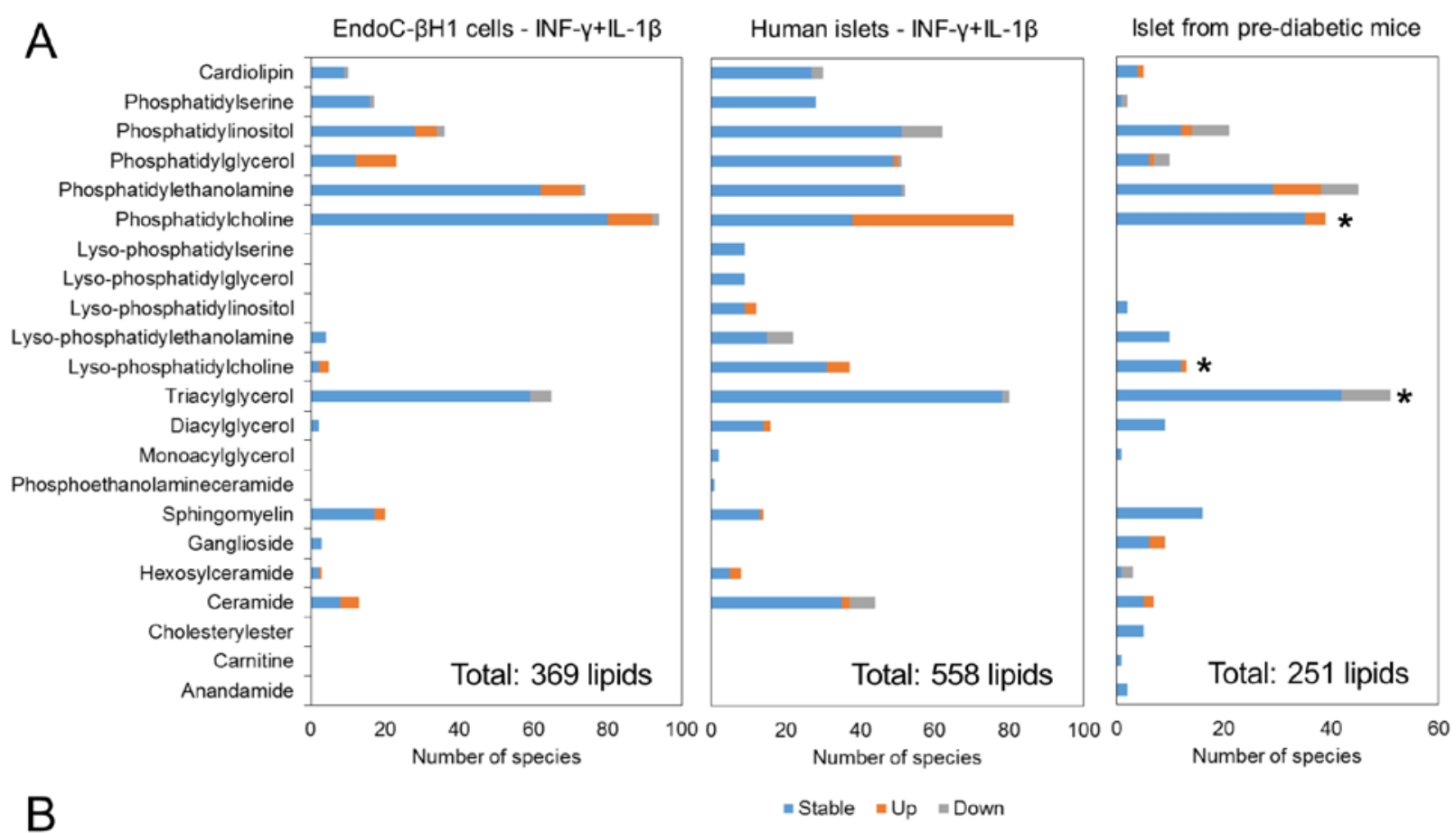

B

Enriched features

\begin{tabular}{|c|c|c|}
\hline \multicolumn{3}{|c|}{ Enriched features } \\
\hline EndoC- $\beta \mathrm{H} 1$ cells - INF- $\gamma+\mid \mathrm{L}-1 \beta$ & Human islets - INF- $\gamma+$ IL-1 $\beta$ & Islet from pre-diabetic mice \\
\hline -Phosphatidylglycerol & -Phosphatidylcholine & $\begin{array}{l}\text {-Triacylglycerol with total number of carbon } 58 \text { in } \\
\text { the fatty acid chains }\end{array}$ \\
\hline -Plasmanyl-phosphatidylethanolamine & -Phospholipid with $\mathrm{C} 17$ fatty acyl chain & \\
\hline -C20:5 fatty acyl chains & - Phosphatidylglycerol with fatty acyl chain with 3 & \\
\hline $\begin{array}{l}\text {-Phosphatidylcholine with total number of carbon } 38 \\
\text { in the fatty acid chains } \\
\text { - Phospholipid with } 6 \text { unsaturations } \\
\text { - Triacylglycerol with } 3 \text { unsaturations } \\
\text { - Phospholipid with } 20: 5 \text { fatty acyl chain } \\
\text { - Phosphatidylcholine with C18:0 fatty acid chains }\end{array}$ & -Phospholipid with 22:5 fatty acyl chain & \\
\hline
\end{tabular}


bioRxiv preprint doi: https://doi.org/10.1101/2020.03.23.004481; this version posted December 23, 2020. The copyright holder for this preprint (which was not certified by peer review) is the author/funder. All rights reserved. No reuse allowed without permission.

Figure 2

\begin{tabular}{|c|c|c|c|c|c|c|}
\hline \multirow{3}{*}{ Common features } & \multicolumn{6}{|c|}{ Sample } \\
\hline & \multicolumn{2}{|c|}{ EndoC- $\beta \mathrm{H} 1$ cells - INF- $\gamma+\mid \mathrm{LL}-1 \beta$} & \multicolumn{2}{|l|}{ Human islets $-I N F-\gamma+\mid \mathrm{L}-1 \beta$} & \multicolumn{2}{|l|}{ Islets from pre-diabetic mice } \\
\hline & Species & $\mathrm{FC}$ & Species & FC & Species & FC \\
\hline \multirow{6}{*}{$\begin{array}{l}\text { Increased levels of } \\
\text { LysoPC }\end{array}$} & $\mathrm{PC}(0: 0 / 16: 0) \_\mathrm{A}$ & 0.91 & $\mathrm{PC}(0: 0 / 16: 0) \_\mathrm{B}$ & 0.27 & $\mathrm{PC}(20: 1 / 0: 0)$ & 0.35 \\
\hline & $\mathrm{PC}(0: 0 / 18: 0)$ & 0.72 & $\mathrm{PC}(0: 0 / 18: 0) \_\mathrm{B}$ & 0.24 & & \\
\hline & $\mathrm{PC}(0: 0 / 18: 1) \_\mathrm{A}$ & 0.78 & $\mathrm{PC}(0: 0 / 18: 1) \_\mathrm{B}$ & 0.32 & & \\
\hline & & & $\mathrm{PC}(17: 1 / 0: 0)$ & 0.25 & & \\
\hline & & & PC(17:0/0:0)_B & 0.27 & & \\
\hline & & & $\mathrm{PC}(22: 2 / 0: 0)$ & 0.22 & & \\
\hline \multirow{21}{*}{$\begin{array}{l}\text { Increased levels of } \\
\text { PC with very long, } \\
\text { polyunsuaturated } \\
\text { fatty acids }\end{array}$} & $\mathrm{PC}(16: 0 / 20: 5)$ & 0.46 & $\mathrm{PC}(15: 0 / 20: 4)$ & 0.29 & $\mathrm{PC}(16: 0 / 22: 5) ; \mathrm{PC}(18: 1 / 20: 4)$ & 0.60 \\
\hline & $\mathrm{PC}(18: 0 / 20: 3) \_\mathrm{B}$ & 0.54 & $\mathrm{PC}(15: 0 / 22: 6)$ & 0.22 & $\mathrm{PC}(18: 1 / 22: 6)$ & 0.87 \\
\hline & $\mathrm{PC}(18: 0 / 22: 3)$ & 0.56 & $\mathrm{PC}(16: 0 / 20: 3) ; \mathrm{PC}(18: 1 / 18: 2)$ & 0.29 & $\mathrm{PC}(20: 2 / 22: 6)$ & 0.59 \\
\hline & $\mathrm{PC}(18.0 / 20.6)$ & 0.93 & $\mathrm{PC}(16: 0 / 22: 5) ; \mathrm{PC}(18: 1 / 20: 4) ;$ & 0.53 & & \\
\hline & $\mathrm{PC}(18: 1 / 20: 3) \_\mathrm{B}$ & 0.48 & 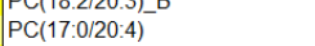 & 0.24 & & \\
\hline & & 0.80 & & 0.30 & & \\
\hline & $\mathrm{PC}(18: 1 / 20: 4) ; \mathrm{PC}(16: 0 / 22: 5)$ & 0.00 & $\mathrm{PC}(17: 0 / 22: 5) ; \mathrm{PC}(19: 1 / 20: 4)$ & 0.00 & & \\
\hline & PC(18:1/20:5) & 0.40 & $\mathrm{PC}(17: 1 / 20: 4)$ & 0.17 & & \\
\hline & & & $\mathrm{PC}(18: 0 / 20: 4) \cdot \mathrm{PC}(18: 1 / 20: 3)$ В & 0.16 & & \\
\hline & & & $\mathrm{PC}(18: 0 / 22: 5)$ & 0.17 & & \\
\hline & & & $\mathrm{PC}(18: 0 / 22: 6)$ & 0.13 & & \\
\hline & & & $\mathrm{PC}(18: 1 / 20: 5) ; \mathrm{PC}(18: 2 / 20: 4) ;$ & 021 & & \\
\hline & & & $\mathrm{PC}(16: 0 / 22: 6) ; \mathrm{PC}(16: 1 / 22: 5)$ & 0.21 & & \\
\hline & & & $\mathrm{PC}(18: 1 / 22: 6) ; \mathrm{PC}(20: 3 / 20: 4)$ & 0.14 & & \\
\hline & & & $\mathrm{PC}(18: 2 / 20: 1)$ & 0.22 & & \\
\hline & & & $\mathrm{PC}(18: 2 / 20: 2) \mathrm{PC}(18: 1 / 20: 3) \mathrm{A}$ & 0.24 & & \\
\hline & & & PC(20:1/20:4):PC(20:2/20:3) & 0.23 & & \\
\hline & & & $\mathrm{PC}(20: 2 / 20: 4)$ & 0.32 & & \\
\hline & & & $\mathrm{PC}(20: 3 / 22: 4)$ & 0.33 & & \\
\hline & & & $\mathrm{PC}(20: 4 / 22: 1)$ & 0.14 & & \\
\hline & & & $\mathrm{PC}(22: 4 / 22: 6)$ & 0.36 & & \\
\hline \multirow{9}{*}{$\begin{array}{l}\text { Decreased levels } \\
\text { of TG }\end{array}$} & TG44:1 & -0.87 & $\mathrm{TG}(54: 1)$ & -0.42 & TG(52:3) & -0.61 \\
\hline & TG49:2 & -0.44 & TG(56:2) & -0.42 & TG(56:3) & -0.67 \\
\hline & TG49:3 & -0.64 & & & $\mathrm{TG}(54: 3)$ & -0.47 \\
\hline & TG50:3 & -0.19 & & & TG(58:6) & -0.91 \\
\hline & TG51:3 & -0.40 & & & TG(56:4) & -0.77 \\
\hline & TG53:3 & -0.18 & & & TG(58:8) & -0.68 \\
\hline & & & & & $\mathrm{TG}(52: 2)$ & -0.33 \\
\hline & & & & & TG(56:8) & -0.82 \\
\hline & & & & & TG(58:9) & -0.75 \\
\hline & & \multicolumn{3}{|c|}{ Fold change } & & \\
\hline & & & \begin{tabular}{c|c}
-0.5 & 0.0 \\
\end{tabular} & 1.0 & & \\
\hline
\end{tabular}


Figure 3
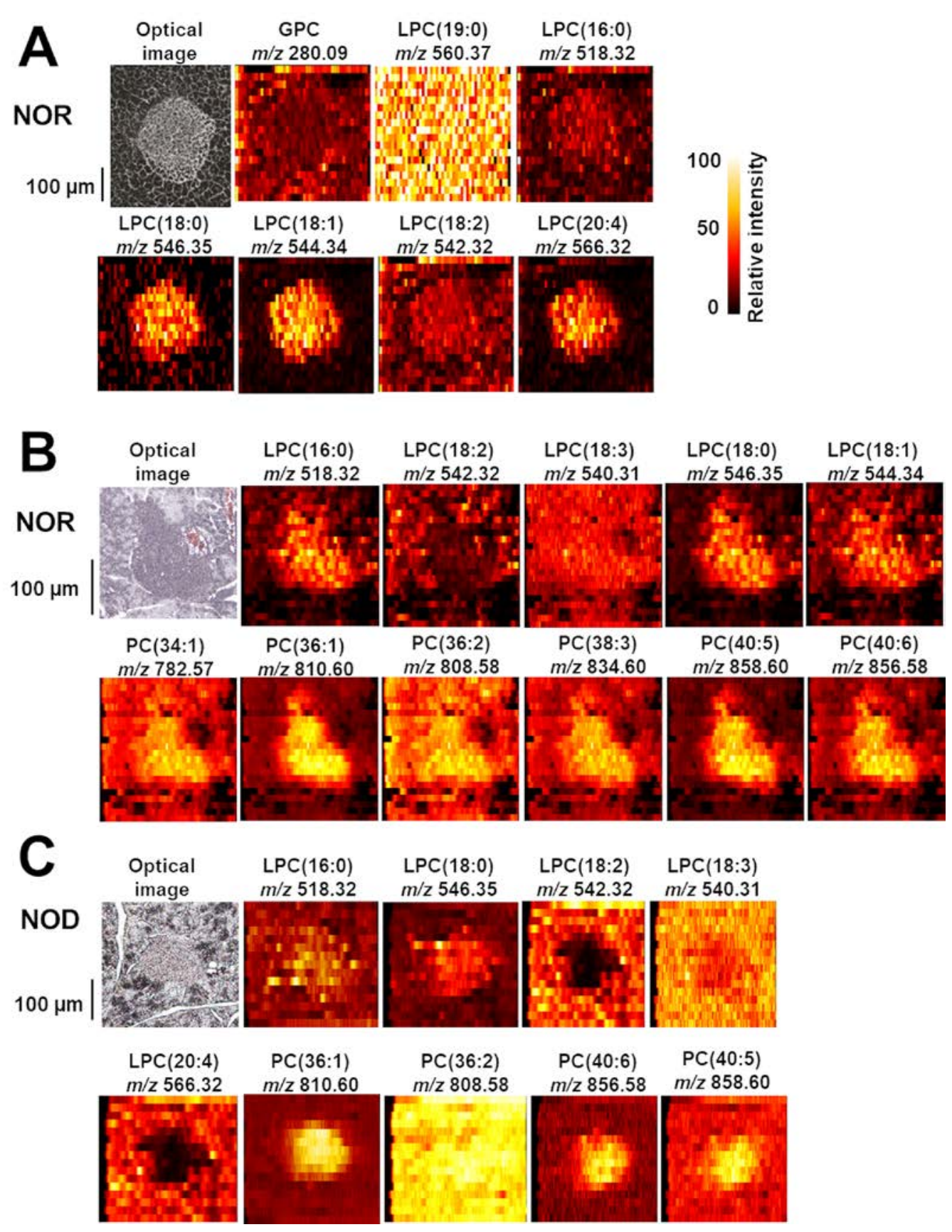
bioRxiv preprint doi: https://doi.org/10.1101/2020.03.23.004481; this version posted December 23, 2020. The copyright holder for this preprint (which was not certified by peer review) is the author/funder. All rights reserved. No reuse allowed without permission.

Figure 4

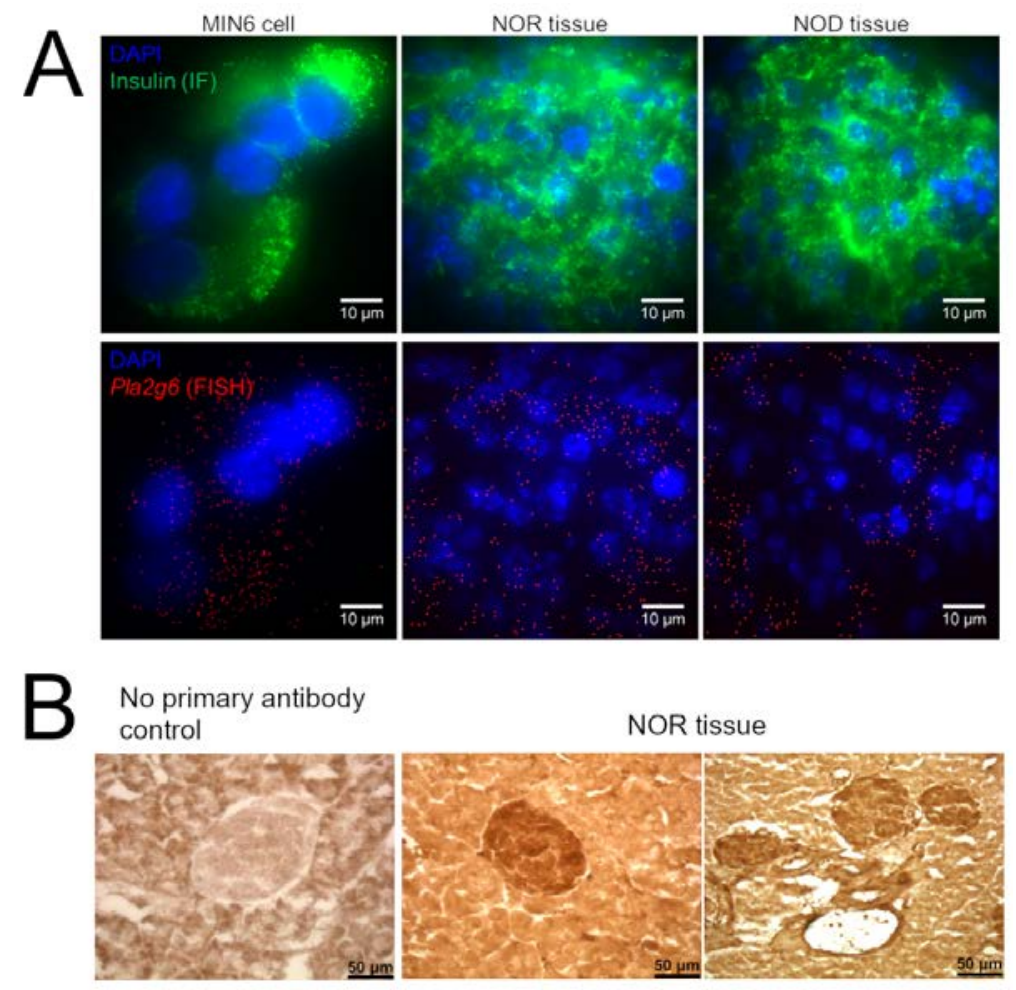




\section{Figure 5}

A

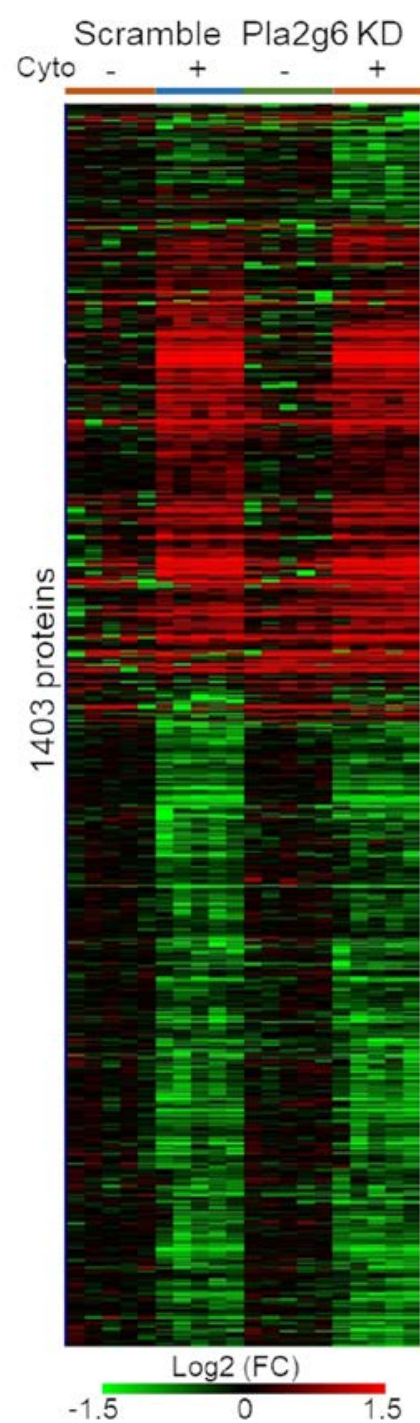

B

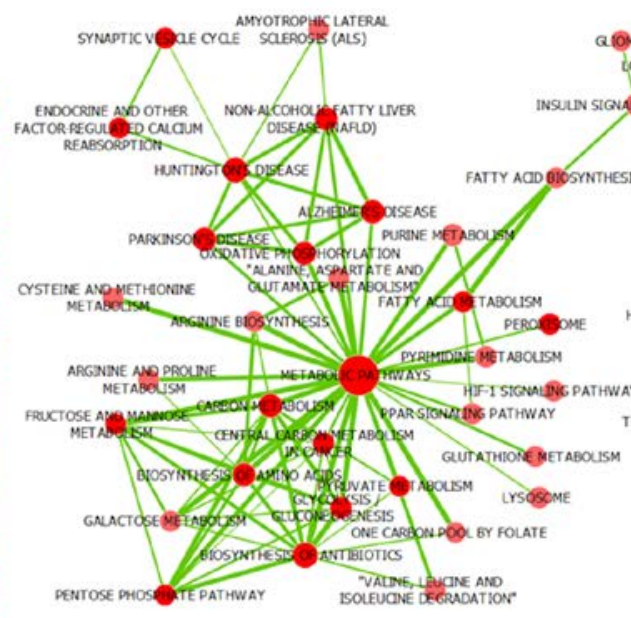

C Scramble Pla2g6 KD

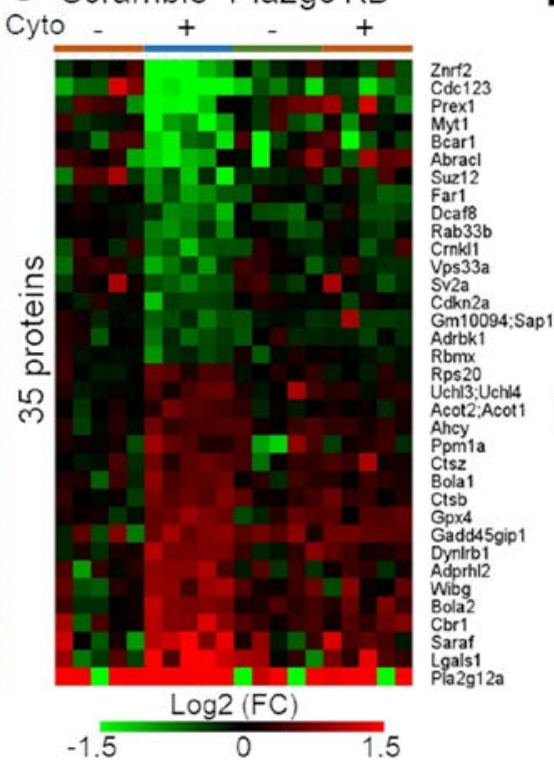

D

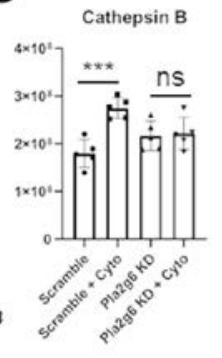

$\mathbf{F}$

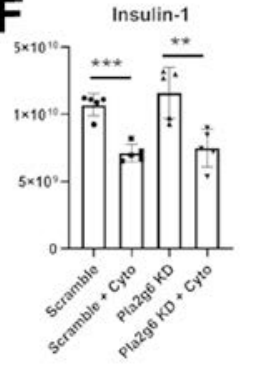


Figure 6

A

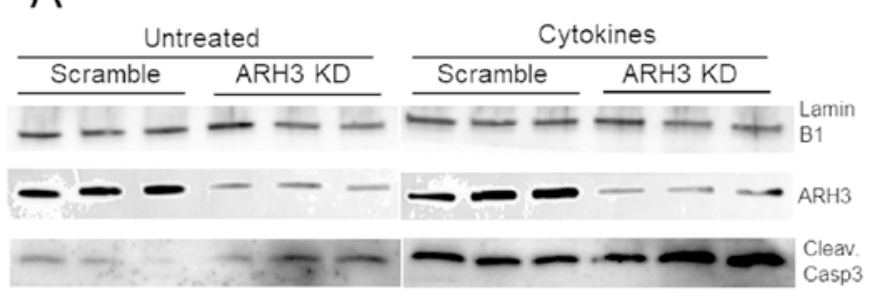

B

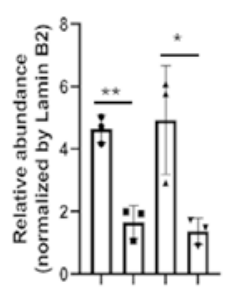

C Cleaved Caspase 3

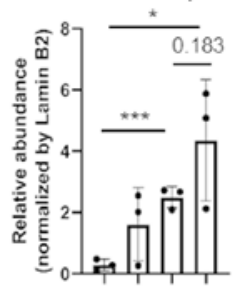

D

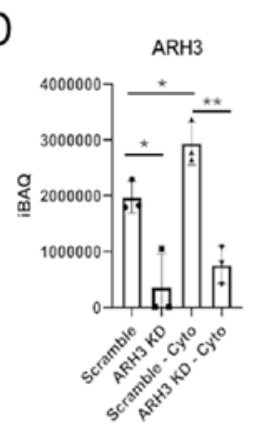

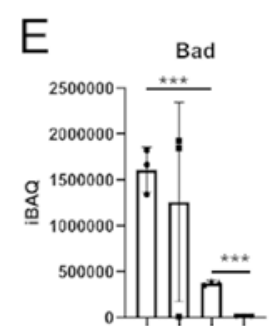

F Pdcd4

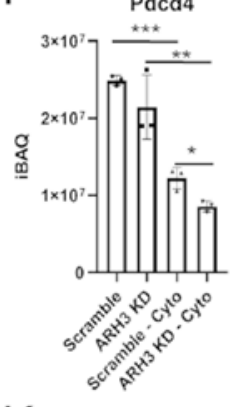

$\mathrm{K}$

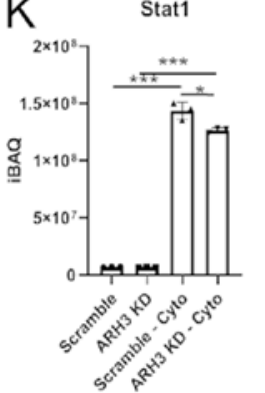

I H2-K1

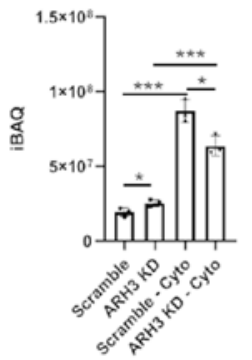

$\mathrm{N}$

Cxc19

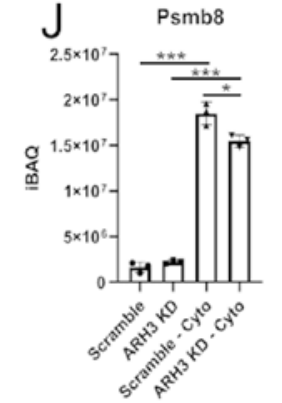

O

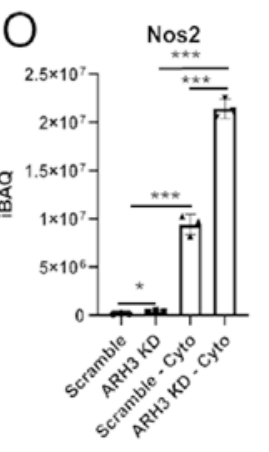

P

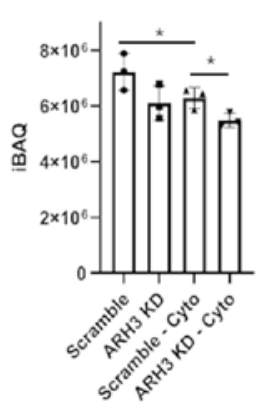

$30^{\circ} x^{\circ}+0^{\circ} 4^{\circ}$

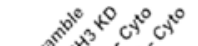

$G \stackrel{5}{\text { Parp12 }}$

(15000007)

$\mathrm{H}$
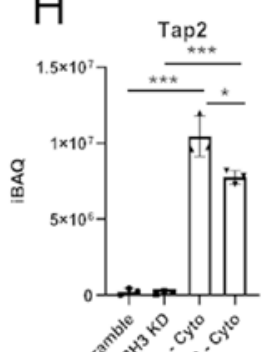

50 के

M $\quad \mathrm{Ccl} 2$

L Stat3

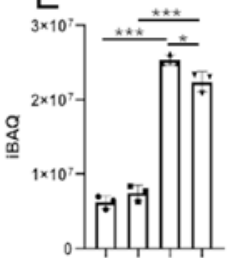
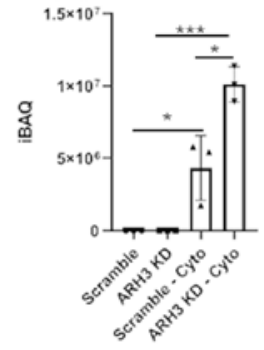

Q

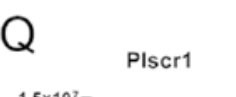

$\mathrm{R} \quad$ sptlc1

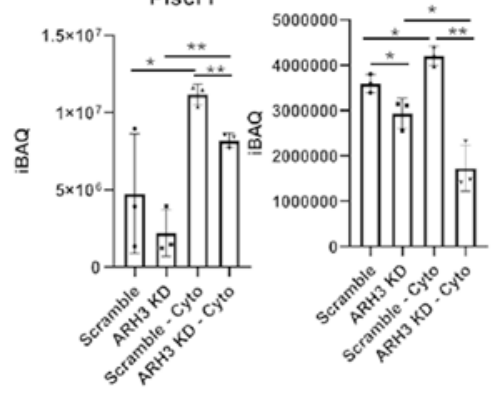

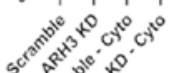

sin 


\section{Figure 7}

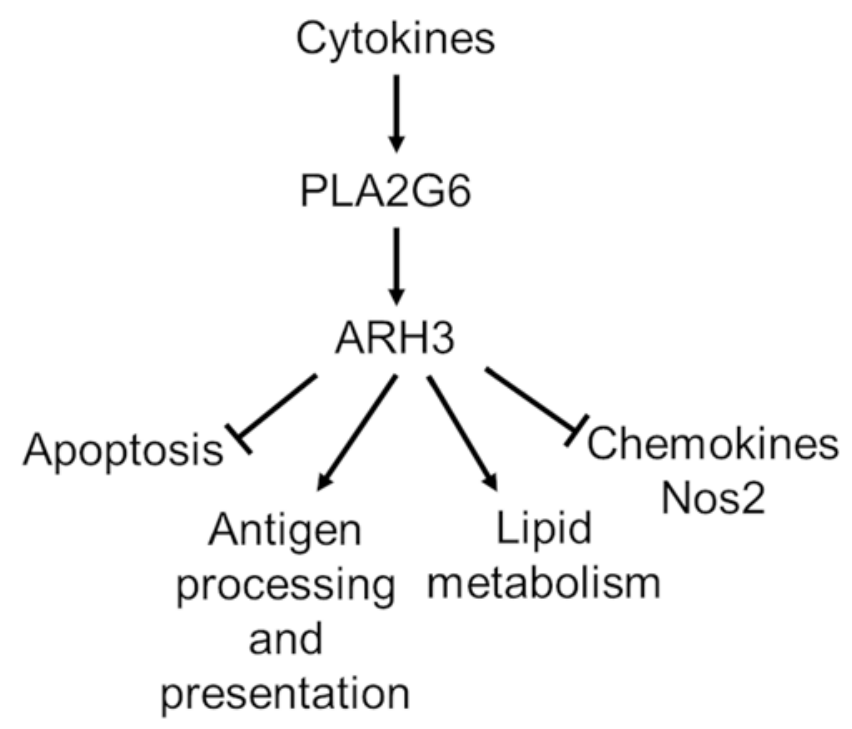




\section{Figure S1}

A
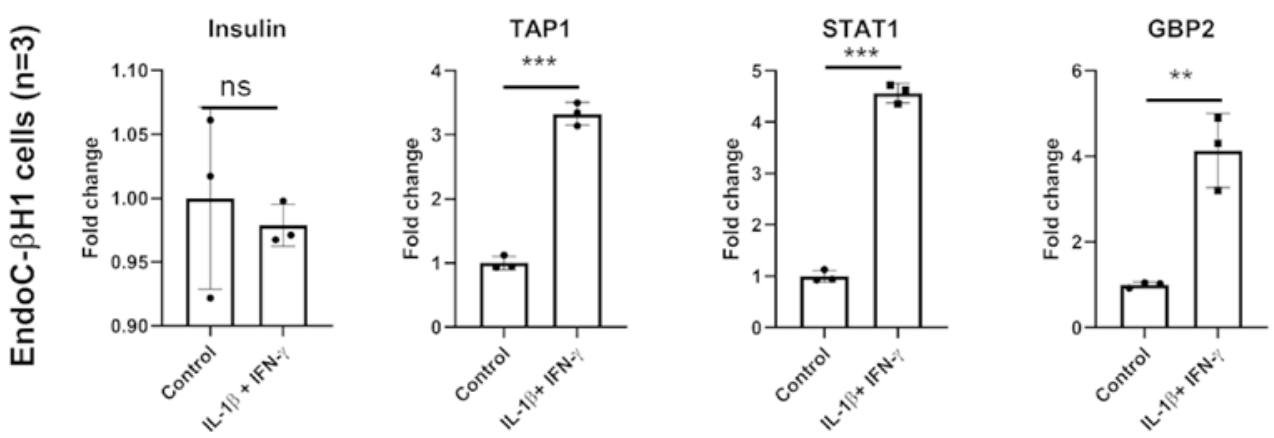

B
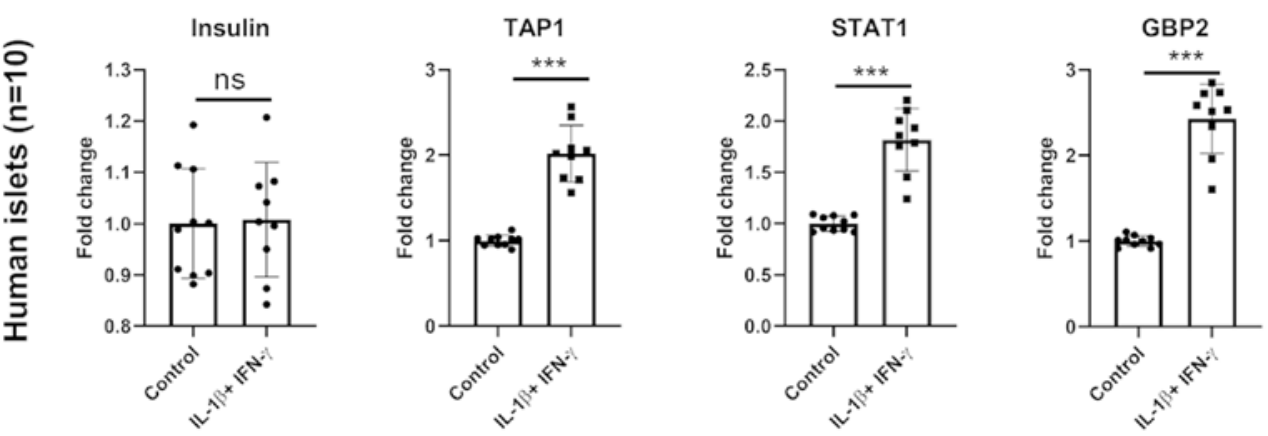

C
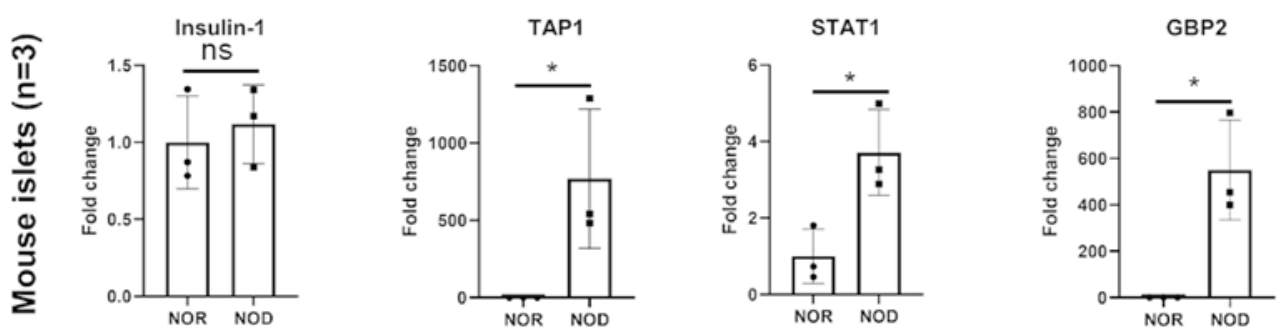